\title{
A Survey to Reduce STDs Infection in Mongolia and Big Data Virtualization Propagation
}

\author{
Woo-Hyuk Choi ${ }^{1}$ (D) and Jun-Ho Huh ${ }^{2, *}$ (D) \\ 1 Department of Medicine, Mongolian National University of Medical Sciences, Ulaanbaatar 14200, Mongolia; \\ pmm19d1025@st.mnums.edu.mn \\ 2 Department of Data Science, National Korea Maritime and Ocean University, Busan 46252, Korea \\ * Correspondence: 72networks@kmou.ac.kr
}

Citation: Choi, W.-H.; Huh, J.-H A Survey to Reduce STDs Infection in Mongolia and Big Data Virtualization Propagation. Electronics 2021, 10, 3101. https://doi.org/10.3390/ electronics10243101

Academic Editor: Amir Mosavi

Received: 21 August 2021

Accepted: 24 November 2021

Published: 13 December 2021

Publisher's Note: MDPI stays neutral with regard to jurisdictional claims in published maps and institutional affiliations.

Copyright: (c) 2021 by the authors. Licensee MDPI, Basel, Switzerland. This article is an open access article distributed under the terms and conditions of the Creative Commons Attribution (CC BY) license (https:// creativecommons.org/licenses/by/ $4.0 /)$.
Abstract: Sexually transmitted diseases refer to clinical syndromes and infections that are acquired and transmitted through sexual activity. Worldwide, more than 340 million cases of sexually transmitted disease occur each year, placing a great burden on individuals as well as communities and countries. The proportion of sexually transmitted diseases (STDs) in Mongolia is relatively high due to their inadequate treatment technologies, religious or local customs, and regional differences. It is rather difficult to grasp the exact number of patients as these diseases are considered ones that should not be disclosed to others. Therefore, this study aims to accurately identify sexually transmitted diseases in Mongolia and reduce infection through an analytic approach of big data virtualization propagation.

Keywords: sexually transmitted diseases (STDs); big data virtualization; developing countries; Mongolia STDs; Mongolia STDs monitoring; virtualization R programming language; big data

\section{Introduction}

Big data analytic tools provided by bioinformaticians have allowed unprecedented insights into many aspects of medicine [1].

Infectious diseases through sexual activity have historically been recognized as being against ethical and religious values and has been recognized as a hidden disease until now. Compared with other diseases, STDs are far behind in treatment, while the cases have increased rapidly due to industrialization [2]. STDs refers to various clinical syndromes and infections caused by pathogens that can be acquired and transmitted through sexual activity [3]. Pathogens transmitted by STDs include bacteria, viruses, protozoa, and fungi. Named by the WTO since 1975 [4], there have been 500,000 cases of STDs or one in every 200,000 people per day [5]. According to the $\mathrm{WHO}$, the annual global incidences of STDs infection is over 340 million. More than 92 million cases were chlamydia infection, 62 million cases were gonorrhea, 174 million cases were trichomoniasis, and 12 million cases were syphilis [6].

Since most STDs are asymptomatic after infection, it places a great burden on individuals and communities and countries in the long term [7]. For instance, in the United States, one-seventh people infected with human immunodeficiency virus (HIV) are unaware of the fact that they are infected, and this transmission accounts for one-third of new infections every year, so STDs are a dangerous disease [8].

In the 21st century, treatment options for STDs are limited due to the increase in antibacterial resistance, making the treatment situation more difficult [9].

STDs can be divided into curable STDs and incurable STDs. Curable STDs are gonorrhea, chlamydia trachomatis, syphilis and trichomonas vaginalis infections. Incurable STDs include human immunodeficiency virus (HIV), herpes simplex viruses (herpes simplex virus, HSV), human papillomavirus (HPV), and hepatitis B virus [10]. 
Then, let us take a closer look at the STDs classified as representative above. Gonorrhea was first described in 1989 by the pathogen Neisseria gonorrhoeae 'Albert Nisser'. It is a coffee bean-shaped Gram-negative bacteria that plays a role in causing the STD gonorrhea [11]. The symptoms of gonorrhea are different depending on the region, and $10 \%$ of men and $80 \%$ of women are asymptomatic [12].

Chlamydia trachomatis is a spherical, motile Gram-negative bacteria that causes inflammation in the fallopian tubes, ovaries, and endometrium, and it increases the risk of infertility. It acts as a causative agent of urethritis, conjunctivitis, and lymphogranuloma venereum in both men and women [13].

Syphilis is a chronic and systemic infectious disease caused by treponema pallidum, which is transmitted through lesions and body fluids exposed during direct sexual contact with a syphilis patient or, rarely, through blood transfusion or placental during pregnancy [14].

Trichomonas vaginalis is a STD that mainly causes vaginitis in women as flagellate protozoa parasitize in the genitourinary system of the human body [15].

Human immunodeficiency virus (HIV) is a retrovirus that destroys the human immune system that progresses to acquired immune deficiency syndrome (AIDS). It can be caused by sexual activity, contaminated needles, vertical infection, or administration of infected blood. Cases of AIDS and diseases related to HIV increase every year [16,17].

Although Mongolia has been considered as a low prevalence area of HIV [18,19], it does not mean that the possibility of HIV infection is low as well [20-22]. The rate of sexually transmitted infections (STIs) in Mongolia has been increasing since 1993 [21-23], and this shows that unhealthy sexual relationships are increasing and heightening the risk of HIV infection [22]. The record from 1983 to 1995 shows that the number of syphilis (gonorrhea) (trichomonas) cases increased from 18 to 32 (51 to 142) (47 to 155) per 100,000 [23]. Another factor to be considered is that Mongolia is bordering with China and Russia where HIV infections have been spreading widely [24-27]. It is evident that as the social/human exchange between these countries increases [24], the number of HIV infection cases will escalate proportionally. It should be noted that about half of the STI cases have occurred among young Mongolians under 25 years old $[18,26]$.

Herpes simplex virus (HSV) is a member of the herpesviridae family and is a disease that causes viral diseases in humans. Human papillomavirus (HPV) is a deoxyribonucleic acid (DNA) virus with $55 \mathrm{~nm}$ diameter that infects humans and other animals. So far, more than 130 types of human papillomavirus (HPV) have been discovered and can cause cancers such as cervical cancer and testicular cancer $[27,28]$. Hepatitis B virus (hepatitis B virus) is a contagious disease caused by the hepatitis B Virus (HBV), and it is transmitted by infectious blood or body fluids. Most people have no symptoms, but cirrhosis and liver cancer may develop [29].

STDs are emerging as a major health problem around the world. These STDs are leading to higher incidence and prevalence and serious complications in developing countries. Many countries cannot diagnose or treat simple STDs. Most STDs are estimated to be more than 20 times higher than in developed countries [30].

As a result, STDs in developing countries cause serious social and economic problems and lead to serious mortality [31,32]. For example, in Bangladesh, although the prevalence of AIDS is low, high-risk behaviors and sexually transmitted infections due to the increased risk makes these developing countries very vulnerable to STDs infection [33].

Inadequate sex education is the biggest reason that STDs incidence is higher in developing countries than in developed countries. For example, in Turkey, sex education is not provided in the curriculum. The only sex education is that which tells the difference between men and women in biology class [9]. Therefore, for these reasons, developing countries are inevitably exposed to many risks of STDs.

Mongolia is the same among the countries to be studied in this study. Mongolian people are exposed to STDs due to the lack of sex education in their regular school curricu- 
lum. Mongolians traditionally have sex from the age of 15 and when the body is sexually developed due to the influence of the nomadic lifestyle [34].

In addition, it is estimated that there are many patients with STDs that are not statistically identified because it is difficult to determine the actual number of STDs infection in Mongolia. Even if symptoms of STDs appear, STDs are recognized as a secret disease in Mongolia that is hidden and not treated, making it difficult to understand the actual situation [35].

In this survey/review paper, after analyzing the status of the Mongolian people's medical system, we will find measures to reduce STDs infection in Mongolia by statistically and accurately identifying people infected with STDs in Mongolia. To this end, an analytical approach to big data will be used. In the healthcare field, big data are already used to analyze extensive data through medical records, dietary habits, occupations, etc. and treatment methods are being improved [36]. We will seek ways to reduce STDs infection in Mongolia through this big data-based method.

\section{Materials and Methods}

\subsection{Description of Big Data Use}

The data analyzed in this paper are the following seven types of data. The data for "Gender ratio", "Life expectancy", "Medical expenses (more than 25\% of household expenditure)", "Population density", and "Medical doctor density" are based on data from health indicators published by the World Health Organization [37]. The education index utilizes data published by the Human Development Index [38]. The data were subjected to correlation analysis and regression analysis through the $\mathrm{R}$ programming language to derive meaningful results.

\subsection{Materials and Methods}

We will explain the data used, the materials, and the analysis method. Here, we will focus on the data analyzed and visualized using the $\mathrm{R}$ studio programming language. Therefore, in this paragraph, only the figures and tables analyzed using $R$ studio programming language will be explained.

Figure 1 visualizes the data on population density through treemap analysis using the $\mathrm{R}$ programming language based on population density data published by United Nations (UN). Table 1 contains WHO and Mongolian Ministry of Health data published by the OECD, which was prepared based on Mongolia's major health indicators. This table was used as numerical data for Figure 4.

Figure 4 is based on data from the WHO and Mongolian Ministry of Health, which visualized major health indicators through bar graph analysis using the $\mathrm{R}$ programming language.

Figure 5 visualizes data through circular diagram analysis using the $R$ programming language based on data from an institution in Mongolia called the Center for Health Development.

Meanwhile, Table 2 was prepared on the basis of 'Health indicators (2018)' issued by the Mongolian Ministry of Health and Welfare, and it is a table explaining the current status of medical facilities in Mongolia.

Table 3 compares the STDs of Mongolia and Korea. The source for STDs in Korea is the paper by June Myung Kim et al. (2018), and the source for Mongolia is 'Health indicators (2018)' published by the Ministry of Health and Welfare of Mongolia.

Table 4 is a table that summarizes each administrative district of Mongolia based on the Worldometer. Table 4 is used to visualize Figure 8.

Figure 9 is based on the Worldometer data; the population, region, and Soum of each administrative province of Mongolia were visualized through positive and negative correlation analysis using the $\mathrm{R}$ programming language. In addition, Table 5 contains the script data of the $\mathrm{R}$ programming language for information about each province in Mongolia big data visualization in Figure 9.

Figure 10 is the correlation between the region of Mongolia and the number of Soum analyzed to be correlated in Figure 9. These data were visualized through correlation anal- 
ysis using the $\mathrm{R}$ programming language. Table 6 contains the script data of $\mathrm{R}$ programming language for 'Correlation big data analysis for each province in Mongolia' in Figure 10.

Figure 11, the correlation between the Mongolian region and the number of soums in Figure 10 was visualized through scatterplot analysis using the $\mathrm{R}$ programming language. Table 7 summarizes the data for the scatterplot for area and soums in Figure 11 and the regression analysis derived using the $\mathrm{R}$ programming language in a table format.

Figure 13 is based on data from the WHO is based on data from the WHO; life expectancy and STDs (HIV infection) infection were visualized through correlation analysis using the $\mathrm{R}$ programming language.

Figure 14 is based on data from the WHO; medical density and STDs (HIV infection) infection were visualized through correlation analysis using the $\mathrm{R}$ programming language.

Figure 15 is based on Human Development data; the education index and STDs (HIV infection) infection were visualized through correlation analysis using the $\mathrm{R}$ programming language.

Figure 16 is based on data from the WHO; STDs (HIV infection) infection and life expectancy were visualized through scatterplot analysis using the $\mathrm{R}$ programming language.

Figure 17 is based on the WHO's STDs (HIV infection) infection data; medical density and STDs (HIV infection) infection were visualized through scatterplot analysis using the $\mathrm{R}$ programming language.

Figure 18 is based on data from the WHO and Human Development; STDs (HIV infection) infection and education were visualized through scatterplot analysis using the $\mathrm{R}$ programming language.

Figure 19 contains a bar graph analysis of the global STDs infection rate using the $\mathrm{R}$ programming language every year based on the statistical data of the WHO international STDs.

Tables 8-13 shows STDs (HIV infection) infection and Gender ratio, using the $\mathrm{R}$ programming language based on data from World Health Statistics (2021) and Human Development (2021). The correlation analysis of life expectancy, medical expenses (more than $25 \%$ of household expenditure), population density, medical doctor density, and education index is presented in table format.

Table 14 shows shows the regression analysis between STDs (HIV infection) and life expectancy using the R programming language based on the data of World Health Statistics (2021) published by the WHO.

Table 15 shows the regression analysis between STDs (HIV infection) and density of medical doctors using the R programming language based on the data of World Health Statistics (2021) published by the WHO.

Table 16 shows the regression analysis between STDs (infection) and education using the R programming language based on the data of Human Development (2021) in table format.

Table 17 presents the data of Cho KS et al. (2009) on curable STDs and incurable STDs.

\section{A Survey to Reduce STDs Infection in Mongolia Case Study Using Big Data Virtualization}

For about 20 years, Mongolians have rarely considered their college students marrying or living together without being legally married as a social problem, and as a result, about $54 \%$ of sexually transmitted infections are occurring among young people due to their open sexual relationships, leading to a high risk of reproductive health problems. In addition, venereal infections are one of the continuous major public health issues in Mongolia caused by widespread and unsafe sexual intercourse [17].

Mongolia is a landlocked country in East Asia, which is bordered by Russia to the north and the People's Republic of China and Inner Mongolia Autonomous Region to the south. In 1992, it changed from communism to democracy. Mongolia is the second largest landlocked country after Kazakhstan with an area of 1,564,116 km², according to the indicators announced by the World Bank of the United States in 2019, but with a population of $3,225,000$, it is one of the lowest in the world in terms of population density. 
Of this population, 1,452,000 live in the capital, Ulaanbaatar. Figure 1 shows the population treemap by population density. It can be seen that Mongolia has a very small population density compared to its area compared with other countries in the world.

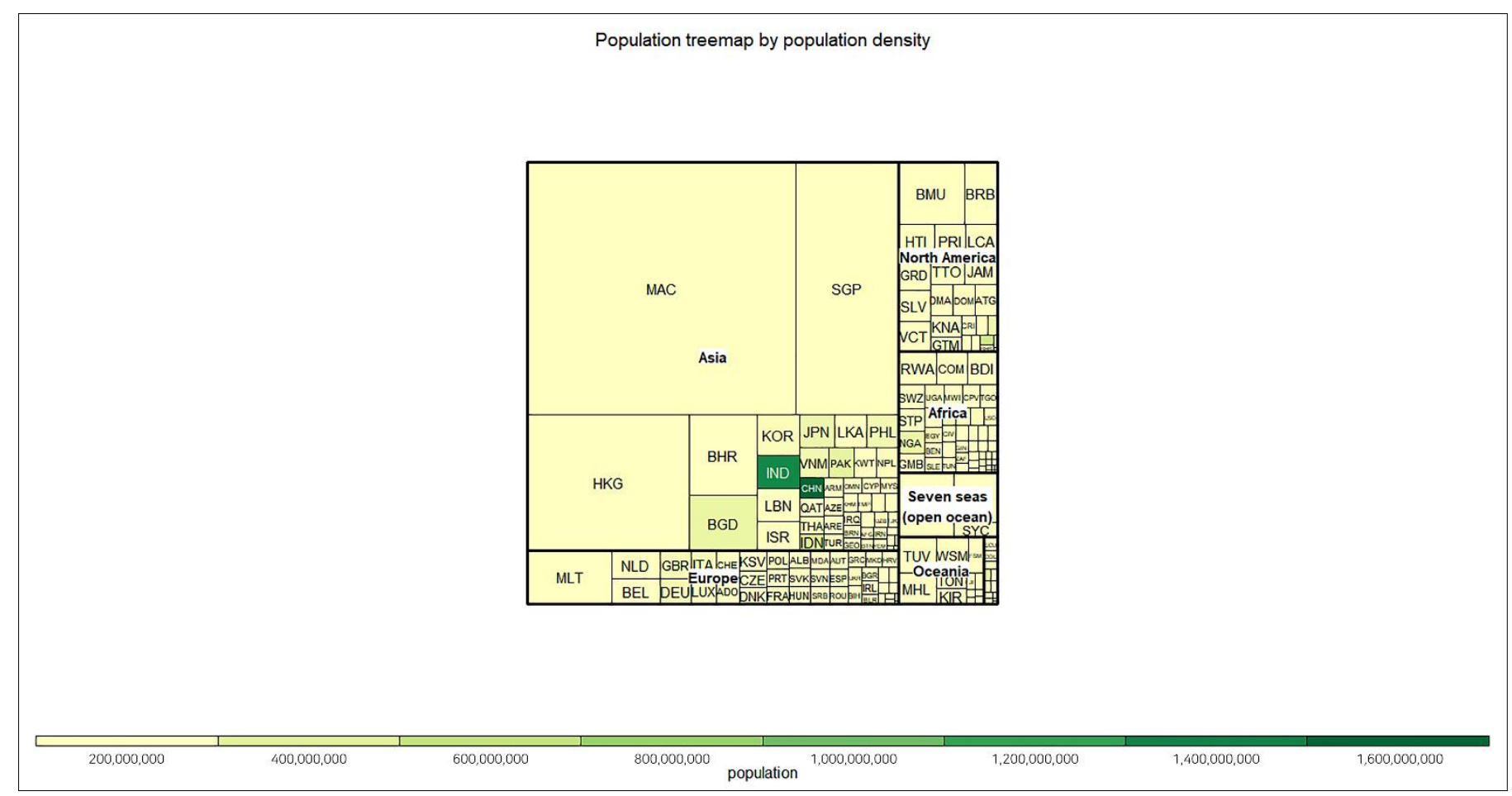

Figure 1. Population treemap of population density virtualization using R programming language.

Figure 1 visualizes data on population density through treemap analysis using the $\mathrm{R}$ programming language based on population density data published by the United Nations (UN).

Mongolia has a unique healthcare system compared with other countries due to the traditional nomadic lifestyle and the high gap between the rich and the poor [39].

\subsection{Mongolian Medical System Status}

3.1.1. Health Insurance Fund (HIF)

Mongolia introduced a mandatory health insurance fund (HIF) for all workers in 1994. The system covers all patients except for cases of chronic infectious diseases [40]. However, in Mongolia, the number of insured persons has been continuously decreasing since 2004 due to the increasing medical expenses, lack of technology, and inadequate services. Therefore, Mongolia's wealthy people even bribe doctors of medical institutions in order to receive better medical services through their personal expenses.

\subsubsection{Mongolia's Medical System}

Mongolia's medical system has three service units and is based on the Russian model [41,42]. It is divided into a central government and local administrative units. The Ministry of Health establishes national health policies, and the Ministry of Finance is in charge of budget allocation in the areas of health and health insurance. The Ministry of Social Welfare and Labor manages and operates health insurance. Figure 2 shows Mongolia's healthcare system. 


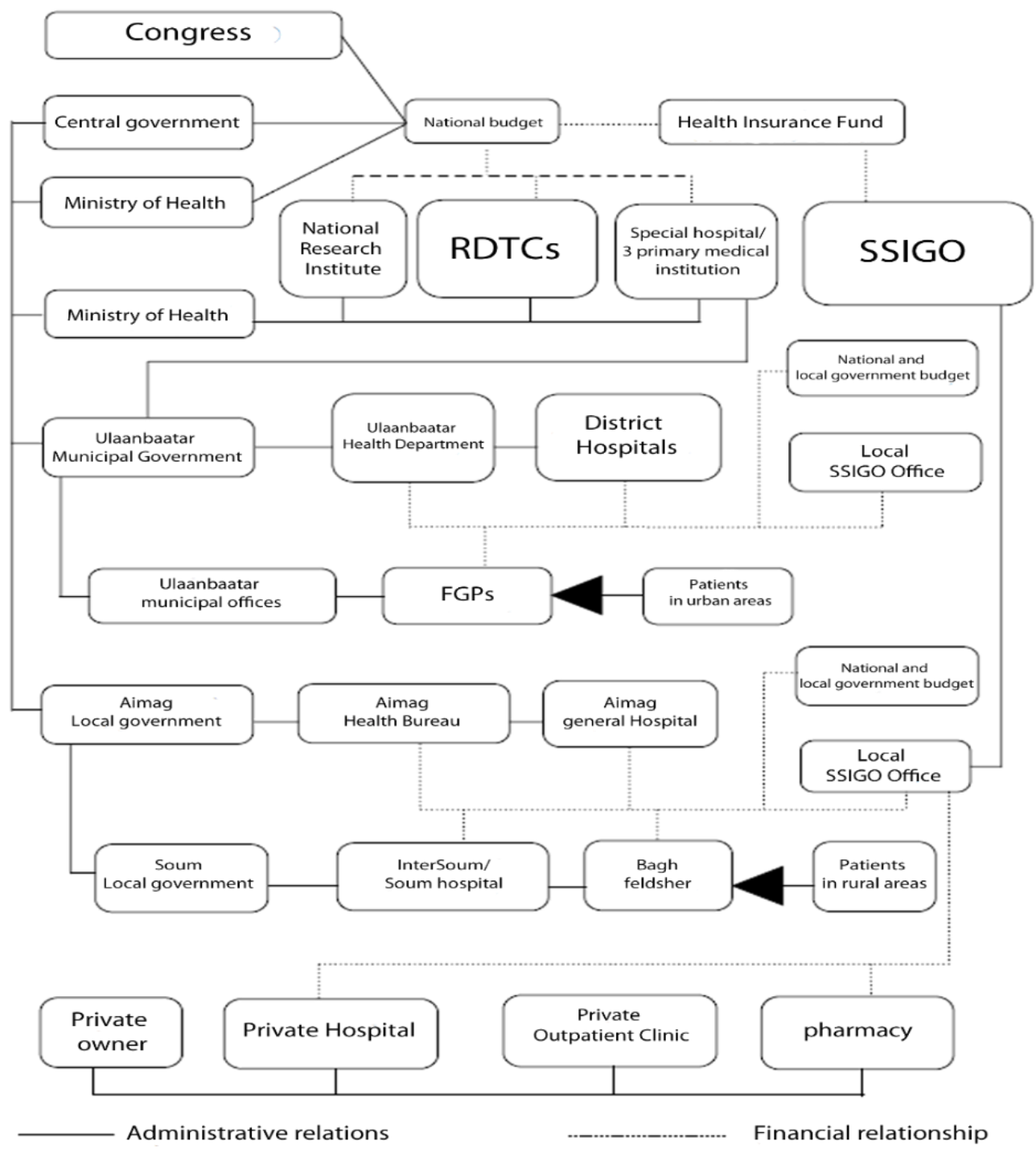

Figure 2. Mongolia's medical healthcare system.

\subsubsection{Major Health Indicators}

In Mongolia, basic health services are provided by family group practice, aimag, soum, and inter-soum hospitals in the capital (Ulaanbaatar). Secondary health services are provided by general hospitals and aimag general hospitals in Ulaanbaatar, and tertiary health services are provided by specialized centers in Ulaanbaatar. Figure 3 shows the Mongolian health administration organization.

\subsubsection{Medical Institution}

Let us compare the average of the Organization for Economic Co-operation and Development (OECD)'s major health indicators with the health-level indicators of Mongolia [43]. Life expectancy in Mongolia is 12 years less than the OECD average of 80.7 years. Mongolia's per capita Gross Domestic Product (GDP) is 5.3 times lower than that of the OECD. In addition, the per capita medical expenses are 3.5\% lower than the OECD (relative to GDP), and the infant mortality rate (per 1000 live births) is 23.15, which is more than five times higher than the OECD average of 4.1. The maternal mortality rate (per 100,000 live births) is nine times higher than that of the OECD. The number of beds per 10 million people is 1.8 times lower than that of the OECD. There are 1.2 times fewer doctors per 100,000 people. Table 1 shows major health indicators. Table 1, 'WHO and Mongolian Ministry of Health' published by the OECD, was prepared based on Mongolia's major 
health indicators. This table was used as numerical data for Figure 4, 'Comparison of average indicators of Mongolia and OECD virtualization using R programming language'.

Figure 4 presents a comparison of medical figures between Mongolia and the OECD using the $\mathrm{R}$ programming language.

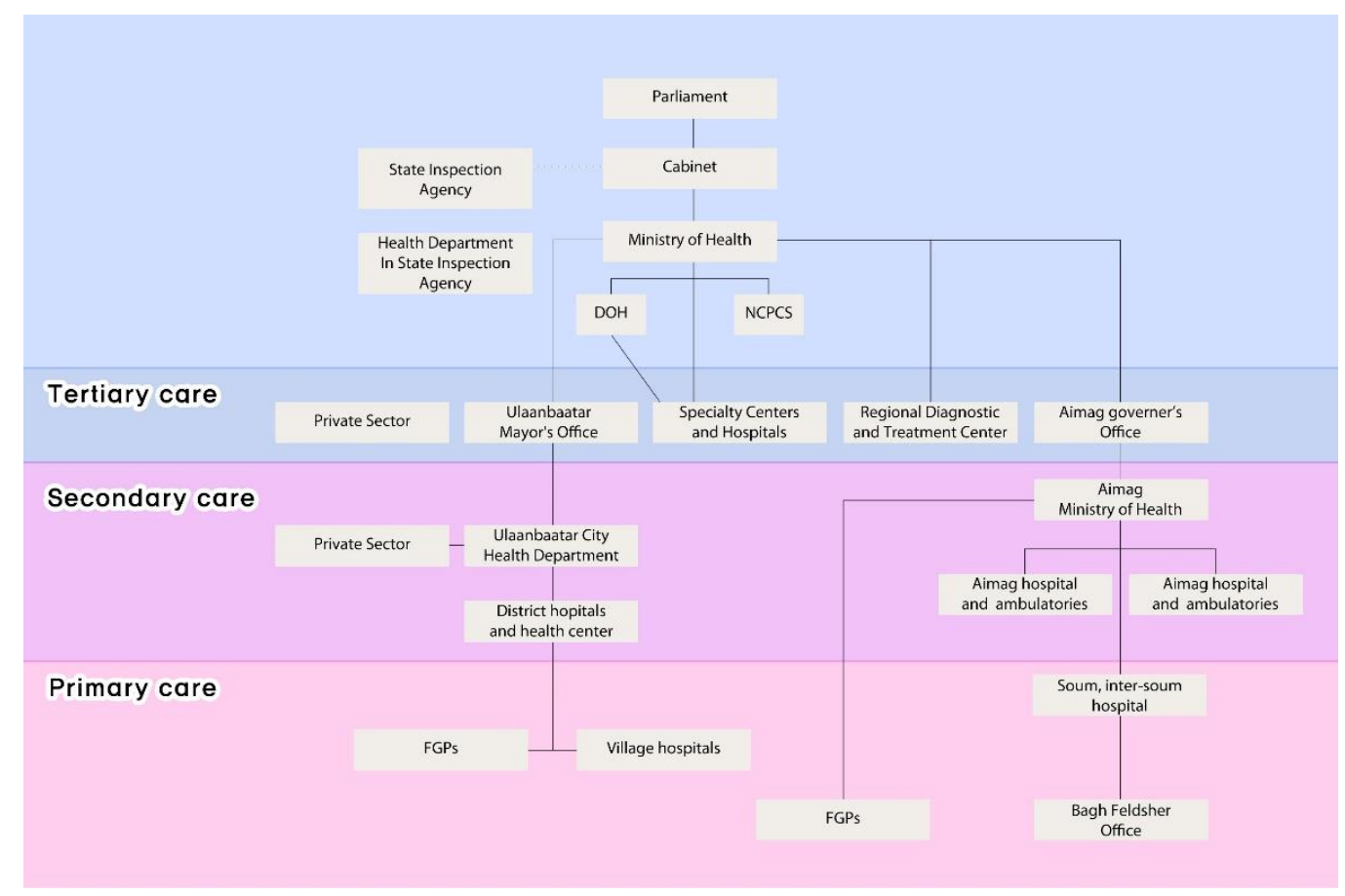

Figure 3. Mongolian health administration organization.
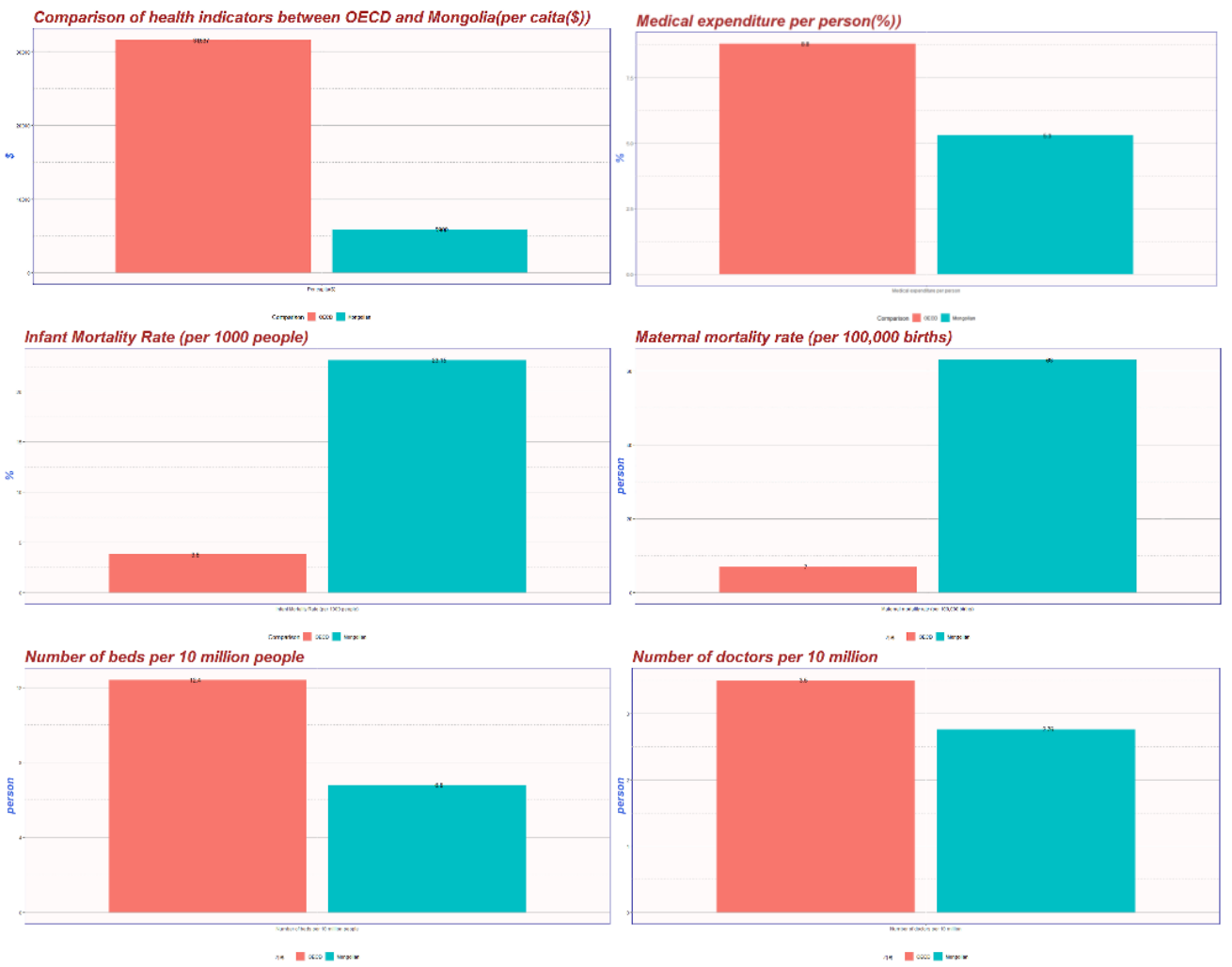

Figure 4. Comparison of average indicators of Mongolia and OECD virtualization using R programming language. 
Table 1. Major health indicators.

\begin{tabular}{cccc}
\hline Indicator Name & Figures & Unit & Calculation Year \\
\hline Population & $2,912,190$ & persons & July 2014 est. \\
Life expectancy & $\begin{array}{c}\text { Average: } 68.98 \\
\text { Male: } 64.72 \\
\text { Female: } 73.45\end{array}$ & age & 2014 est. \\
\hline Per capita & 5900 & $\$$ & 2012 est. \\
\hline Medical expenditure per person & 5.3 of GDP & $\%$ & 2011 \\
\hline Infant mortality rate (per 1000 people) & 23.15 & persons & 2014 est. \\
\hline Maternal mortality rate (per 100,000 births) & 63 & persons & 2010 \\
\hline Number of beds per 10 million people & 6.8 & amount & 2008 \\
\hline Number of doctors per 10 million & 2.76 & persons & 14,083 \\
\hline
\end{tabular}

\subsubsection{Medical Institution}

First, let us take a look at the classification system of medical institutions. Medical institutions can be classified into primary, secondary, and tertiary medical institutions according to different roles. Primary medical institutions are the first medical institutions that people come into contact with, and it refers to healthcare services that combine prevention and treatment together. A secondary medical institution is a medical institution equipped with four or more departments and specialists.

In principle, it is an institution that is responsible for the treatment of outpatients and inpatients requested by the primary medical institution as well as the hospitalization and treatment of emergency patients that occur within the treatment area [44]. Tertiary medical institutions are large-scale hospitals that provide systematic and high-quality medical services to patients requested by primary and secondary medical institutions [45].

Figure 5 shows the proportion of medical institutions in Mongolia. As for medical institutions in Mongolia, there are 550 primary medical institutions, 34 secondary medical institutions, 1254 tertiary medical institutions, and 2049 other medical institutions, totaling 2881 medical institutions. It should be noted that most of the private and starch hospitals are concentrated in Ulaanbaatar, the capital city, and residents living in rural areas receive treatment through Family Group Practice (FGP) and other medical centers.

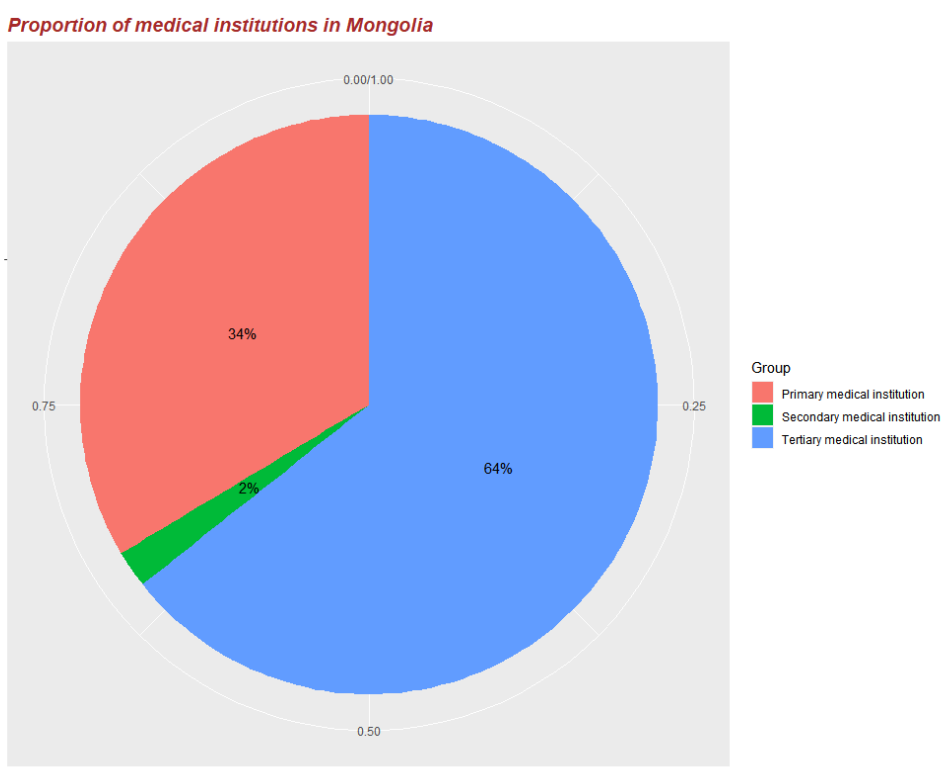

Figure 5. Proportion of medical institutions in Mongolia virtualization using the R programming language. 
Figure 5 is a graph analyzing the first, second, and third medical institutions in Mongolia through the $\mathrm{R}$ programming language. It is estimated that $34 \%$ are primary medical institutions, $2 \%$ are secondary medical institutions, and $64 \%$ are tertiary medical institutions. It shows that Mongolia has an overwhelmingly small number of medical institutions that transition from primary to secondary. Although it cannot prevent patients from choosing medical care, the number of primary and secondary medical institutions must be large, and the balanced development of inter-regional healthcare systems [46-48] can be seen as difficult. Table 2 shows the status of the medical facilities. Table 2 was prepared on the basis of 'Health indicators (2018)' issued by the Mongolian Ministry of Health and Welfare, and it is a table explaining the current status of medical facilities in Mongolia. Figure 6 shows a comparison of medical professionals in Mongolia and the world.

Table 2. Status of medical facilities.

\begin{tabular}{ccc}
\hline Classification & Number \\
\hline \multirow{3}{*}{ Primary medical institution } & Family health centers & 221 \\
& Soum health centers & $271 / 19$ \\
& Intersoum hospitals & 39 \\
\hline \multirow{3}{*}{ Secondary medical institution } & District hospitals & 8 \\
& Rural general hospitals & 6 \\
& Aimag general hospitals & 20 \\
\hline \multirow{2}{*}{ Tertiary medical institution } & Regional diagnostic and & 5 \\
& treatment centers & \\
& Central hospital and & 16 \\
& specialized services & 3 \\
& Maternity hospitals & 45 \\
& Other hospitals & 179 \\
& Private hospitals & 851 \\
& Private clinics & 100 \\
& Sanatoriums & 155 \\
& Orug supply companies & 42 \\
& Drug manufacturers & 855 \\
& Private pharmacies & 46 \\
\hline
\end{tabular}

Total number of medical institutions 2881

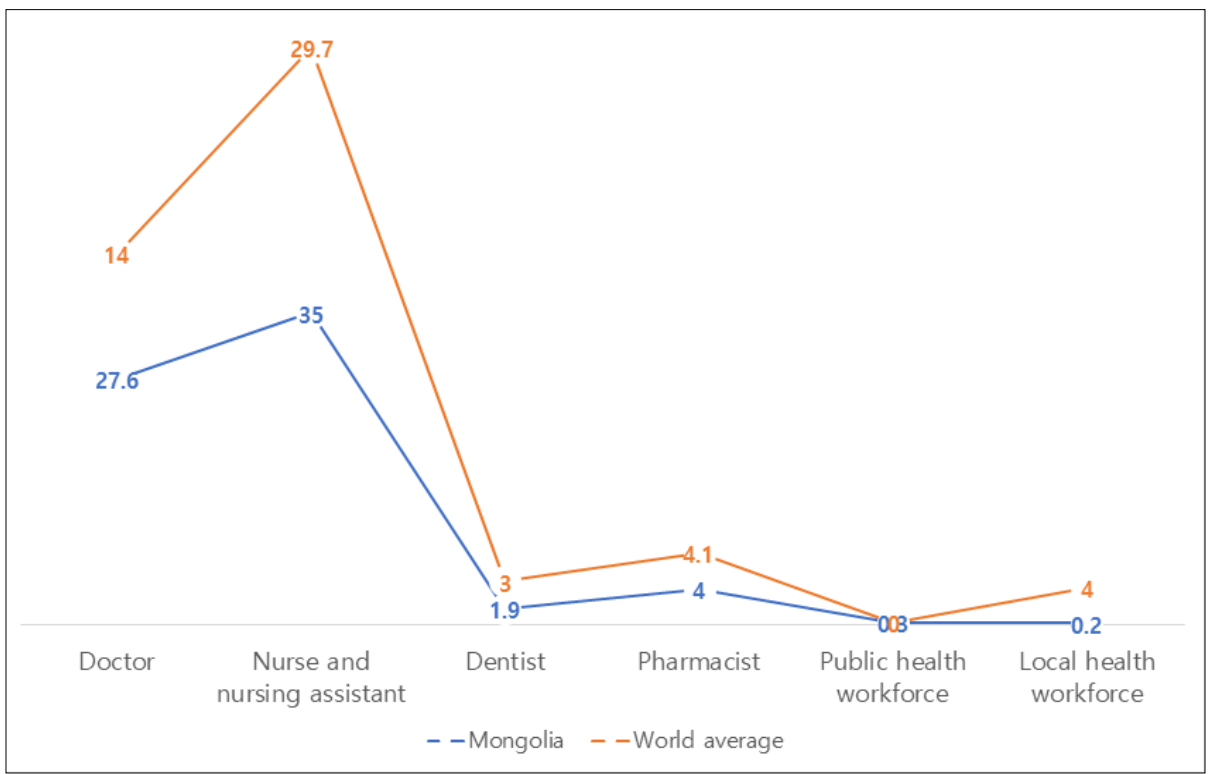

Figure 6. Comparison of medical professionals in Mongolia and the world. 


\subsection{STD in Mongolia}

\subsubsection{Mongolian Gender Perception}

Korean doctor Tae-Jun Lee, known as a doctor who treated Mongolia, said that at that time (1900s), Mongolians, male and female, had syphilis and gonorrhea [49]. It stems from the practice of relying on prayer rather than healing, namely Lamaism. In fact, more than $90 \%$ of Mongolia's population is Lama, and they are reluctant to introduce other religions.

In addition, more than 70\% of Mongolia's population is younger than 35 years old, and under the influence of the former nomadic life, both men and women enjoy drinking culture and are open to sexuality [50]. Most of the cases of STDs in Mongolia come from the poor environment and unsanitary sex life. Since 1990, STDs have spread to all groups, not limited to the vulnerable, and this trend is continuing.

\subsubsection{STDs Outbreak in Mongolia}

In Mongolia, the National Health Report, which is researched and published by the Ministry of Health and Welfare every year, records the health indicators of Mongolian people in detail, including the STDs section. There are more than 30 types of STDs, but only four STDs from the data published by the Mongolian Ministry of Health and Welfare are included in the statistics: gonorrhea (Syphilis), syphilis (Gonorrhea), Trichomoniasis (Trichomoniasis), and HIV / AIDS. In addition, a total of 16,130 STDs were registered in 2018 , accounting for $38.3 \%$ of infectious diseases, which is an increase of $4.7 \%$ compared to the previous year (2017). From 2013 to 2018, the incidence of STDs has been steadily increasing [47]. Figure 7 shows the STDs per 10,000 population.

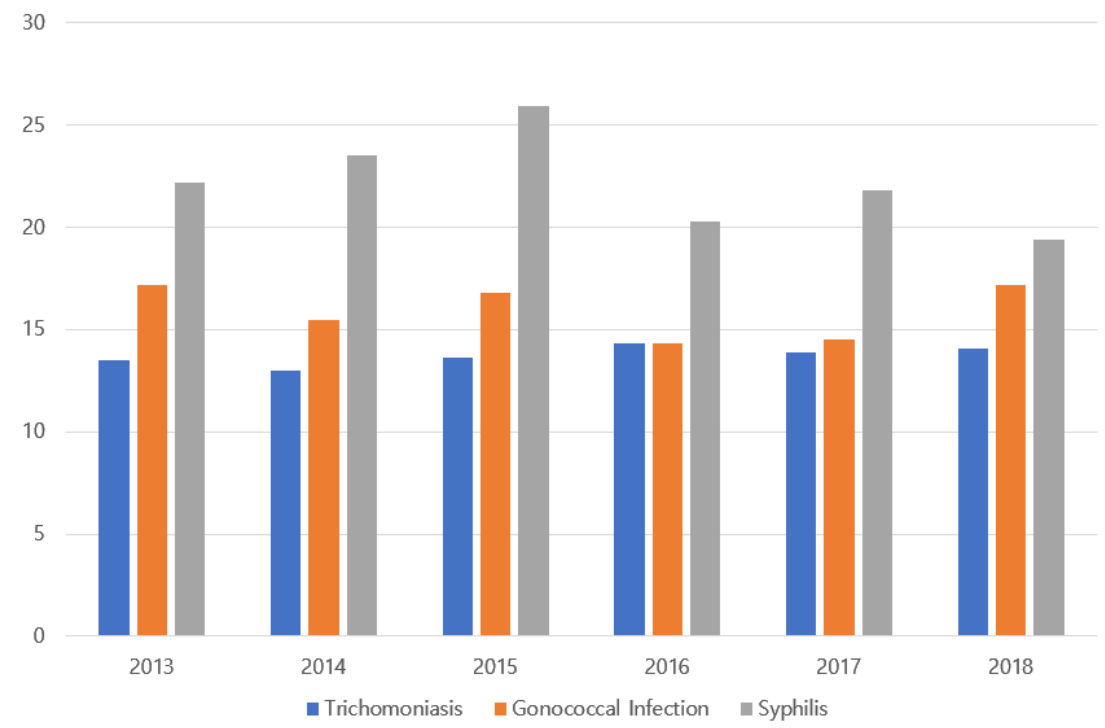

Figure 7. STDs per 10,000 population (2013-2018).

However, these indexes do not fully explain the Mongolian STDs incidence and progress so that an observation was made between the South Korean CDC's data and Mongolian STDs incidence status (as of 2018). First, for syphilis (gonorrhea), the latter indicated that the Mongolian infection rate after considering the two countries' populations was almost three (two) times higher than that of Koreans and, for each 10,000 people, the rate was 50 (30) times higher. At the same time, as for trichomoniasis, the Korean side was approximately 2.5 times higher but for every 10,000, the Mongolian side was six times higher. Finally, the number of Koreans infected by HIV / Aids was 50 times higher, which was 2.5 times higher in incidence. The causality is not clear. However, according to the cohort analysis of infection routes of all the infections discovered from 2006 to 2018, 886 people $(60.1 \%)$ had experienced sexual relations either with the same sex or both sexes (same sex $34.2 \%$, both sexes $25.9 \%$ ), whereas 508 people (34.6\%) had sexual relations with 
the opposite sex [48,51]. It was speculated that the former cases exceeded the latter. It is possible to find a more exact causality for the Mongolian cases if the same analysis can be performed. Table 3 shows STDs comparison between Korea and Mongolia 2018. Table 3 compares the STDs of Mongolia and Korea. The source for STDs in Korea is the paper by June Myung Kim et al. (2018), and the source for Mongolia is 'Health indicators (2018)' published by the Ministry of Health and Welfare of Mongolia.

Table 3. STDs comparison between Korea and Mongolia (2018).

\begin{tabular}{ccccc}
\hline $\begin{array}{c}\text { Infectious } \\
\text { Diseases }\end{array}$ & $\begin{array}{c}\text { Republic of } \\
\text { Korea }\end{array}$ & $\begin{array}{c}\text { Per 10,000 } \\
\text { Population }\end{array}$ & Mongolia & $\begin{array}{c}\text { Per 10,000 } \\
\text { Population }\end{array}$ \\
\hline Syphilis & 2280 & 0.45 & 6670 & 21.8 \\
\hline Gonorrhea & 2361 & 0.47 & 4422 & 14.5 \\
\hline Trichomoniasis & 10,606 & 2.1 & 4247 & 13.9 \\
\hline HIV/AIDS & 1260 & 0.25 & 25 & 0.1 \\
\hline Total & & 14,148 & & \multicolumn{2}{c}{15,364} \\
\hline
\end{tabular}

\section{Idea of Big Data Analytical Approach to Mongolia's STDs}

The big data-based services such as Google Trends, Infographics, etc. have become quite an effective tool for monitoring and forecasting health-related issues or analyzing the big data generated from health and medical fields. Specifically, Google Trends provides seasonal data $[52,53]$ and information about infectious diseases [54-57] including chlamydia [54], along with their outbreaks and epidemic situations of AIDS [58]. When analyzing and forecasting the current and future STDs situations, online queries have been quite useful, but for the last two years, the number of Google queries associated with vaccination has increased [52]. Some of the other topics or issues that Google Trends can provide data (or big data) for the interested parties or public are related to legal matters [59,60], sexting [61], and big data analysis.

Represented by volume, variety, and velocity, big data in the healthcare field are based on the instantaneous consideration of individual differences in the entire population. It is expected to pursue changes in the way people can manage their health and choose medical care. Many countries such as the UK, USA, and Singapore are already building medical platforms in the use of big data in the healthcare sector [62]. Therefore, after constructing and analyzing such big data for STDs in Mongolia, we will ultimately try to find a way to reduce the infection of STDs in Mongolia.

It is likely that Mongolians will acquire inaccurate sexual knowledge, as most of them gain it from public media or people around them. In addition, their school health education just covers a 40-minute reproductive health education course offered one or twice a week. To improve students' health conditions, Mongolian health authorities have been implementing a curriculum to change their risky sexual behaviors since September 2013 and limiting the minimum legal marriage age to 18 [63]. Despite such policies, the marriage age is still considered irrelevant among their people, and having a child without getting married is not a big social problem for them as well. As a nomadic tribe, Mongolians used to live in a movable yurt [64]. Such a living environment led to the tradition of early marriage even within the blood. Additionally, as all the family members were living in the same space, their sexual activities were conducted in an open environment [65]. Consequently, about $54 \%$ of sexually transmitted infections are occurring among young people due to such an open-minded sexual concept [66].

Mongolia's administrative division is divided into 21 provinces (aimag) and 329 counties (soum), and the capital of Ulaanbaatar has the same status as the province (aimag). However, since it has a large area relative to the population, it will be necessary to establish big data in stages. As of 2017, ninety percent of the Mongolian population is connected to a mobile network, so the process of collecting big data is unlikely to be too difficult [67-70]. 
Since Mongolia has many administrative divisions due to its large area, a systematic approach will be required. First of all, as mentioned above, there are not enough data on STDs statistics in Mongolia [67].

In the absence of sufficient data, the analytical approach of big data to reduce STDs in Mongolia in this study is the statistical analysis of each area, population, and soum of 21 states (aimag), and we devised an approach. First, the table below shows the area, population, number of counties, and distance from Ulaanbaatar for each of Mongolia's 21 provinces (aimag). Meanwhile, Table 4 shows information about each province in Mongolia. The first thing to look at here is that Bayan-Ulgii, Khovd, and Omnogovi, which are located the farthest from the capital city of Ulaanbaatar [42,67], need special attention and attention to STDs infection. Figure 8 shows information about each province in Mongolia.

The result of the above data analysis shows that the number of soums increased as the area increased. Based on the statistical data analysis result, an attempt was made to devise a solution to reduce STDs infection effectively.

First, many test and consultation facilities for STDs should be set up and in Mongolia, where people are vulnerable to infectious diseases, only 56 STDs (including HIV) testing and consulting facilities are available nationwide [68]. As most of STDs rarely show initial symptoms that allow early detection, The Center for Disease Control and Prevention (CDC) advises to receive a test even if there are not any particular symptoms one to two weeks after the last doubtful sexual contact [69]. Thus, it is essential to arrange enough testing and consulting facilities before the personal or national damages escalate.

Table 4. Information about each province in Mongolia.

\begin{tabular}{|c|c|c|c|c|}
\hline Name & Area $\left(\mathrm{km}^{2}\right)$ & Population & Soums & Distance from Ulaanbaatar $(\mathbf{k m})$ \\
\hline Arhangai & 55,300 & 93,135 & 19 & 454 \\
\hline Bayan-Ulgii & 45,704 & 90,404 & 13 & 1278 \\
\hline Bayankhongor & 115,977 & 84,807 & 20 & 506 \\
\hline Bulgan & 48,733 & 60,603 & 16 & 270 \\
\hline Darkhan-Uul & 3275 & 101,879 & 4 & 181 \\
\hline Dornod & 123,597 & 77,579 & 14 & 635 \\
\hline Dornogovi & 109,472 & 68,606 & 14 & 470 \\
\hline Dundgovi & 74,690 & 44,762 & 15 & 256 \\
\hline Govi-Altai & 141,447 & 56,587 & 18 & 886 \\
\hline Govisoumber & 5540 & 16,926 & 3 & 201 \\
\hline Khentii & 80,325 & 73,663 & 18 & 228 \\
\hline Khovd & 76,060 & 87,954 & 16 & 1133 \\
\hline Khovsgol & 100,628 & 134,318 & 24 & 521 \\
\hline Omnogovi & 165,380 & 63,307 & 15 & 1122 \\
\hline Orkhon & 844 & 90,700 & 2 & 261 \\
\hline Ovorkhangai & 62,875 & 113,157 & 19 & 373 \\
\hline Selenge & 41,152 & 107,513 & 17 & 276 \\
\hline Sukhbaatar & 82,287 & 59,810 & 13 & 263 \\
\hline Tov & 74,042 & 91,660 & 27 & 84 \\
\hline Uvs & 69,585 & 82,758 & 19 & 1015 \\
\hline Zavkhan & 82,455 & 70,546 & 24 & 1023 \\
\hline
\end{tabular}




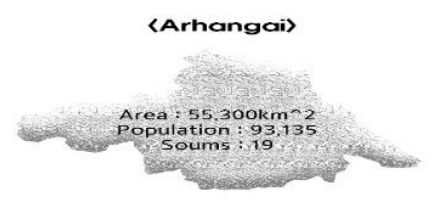

〈Bulgan〉

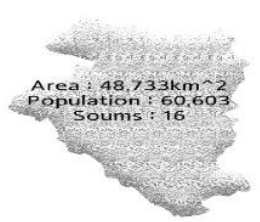

〈Dornogovi〉

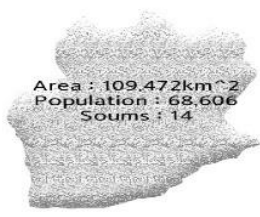

〈Govisumber)

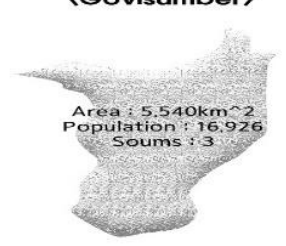

〈Khovsgol〉

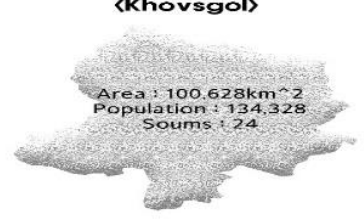

〈Ovorkhangai〉

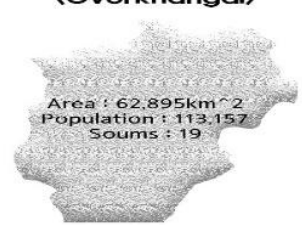

$\langle$ TTov〉

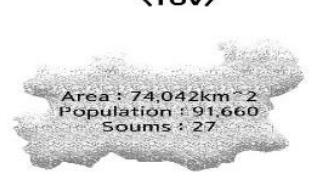

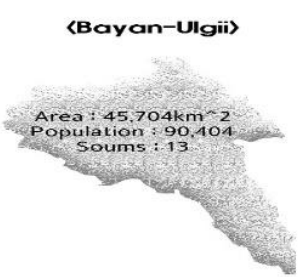

〈Darkhan-Uul〉

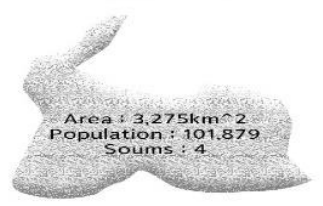

〈Dundgovi)

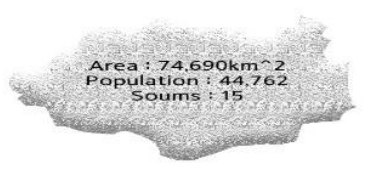

〈Khentii)

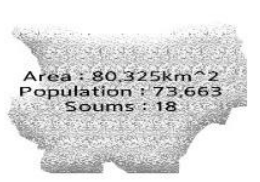

〈Omnogovi〉

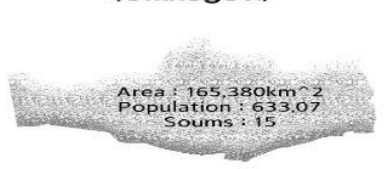

〈Selenge〉

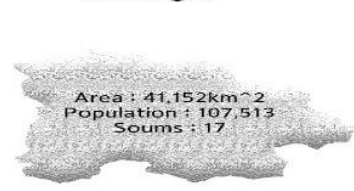

〈Uvs〉

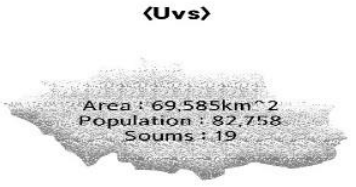

〈Bayankhongor)

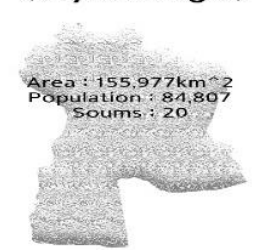

〈Dornod)

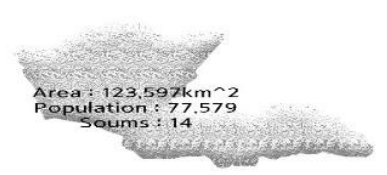

〈Govi-Altai〉

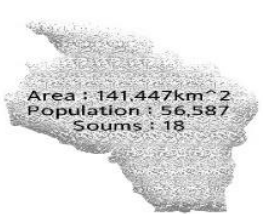

〈Khovd)

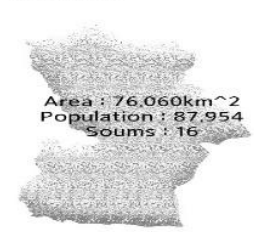

〈Orkhon〉

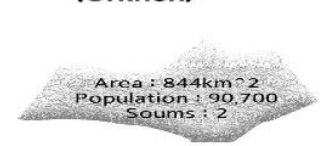

〈Sukhbaatar〉

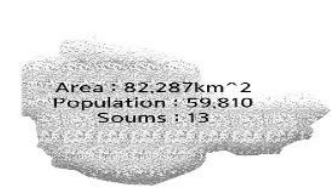

〈Zavkhan〉

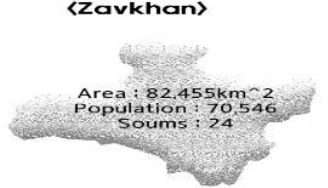

Figure 8. Information about each province in Mongolia.

A systematic STDs treatment facility should be set up. In the above, the big data analysis of STDs has been divided into three healthcare services so that the systemic treatment systems should be arranged according to individual STDs incidences and distributions. It is expected that the Mongolian STDs infections will be reduced definitely based on the big data analysis if the such consulting, testing, and treatment facilities can be secured 
sufficiently. Table 4 is a table that summarizes each administrative district of Mongolia based on the Worldometer source. Table 4 is used to visualize Figure 8.

Next, we analyze the area, population, and state (aimag) through the R programming language.

Figure 9 visualizes the correlation analysis for the number of areas, populations, and soums in red for positive correlations and blue for negative correlations through the $\mathrm{R}$ programming language. Below is the script for Figure 9. Table 5 shows information about each province in the Mongolian big data visualization script. Figure 9 is based on the Worldometer data and shows the population, region, and soum of each administrative province of Mongolia, which were visualized through positive and negative correlation analysis using the $\mathrm{R}$ programming language. Table 5 contains the script data of the $\mathrm{R}$ programming language for the information about each province in the Mongolia big data visualization in Figure 9.

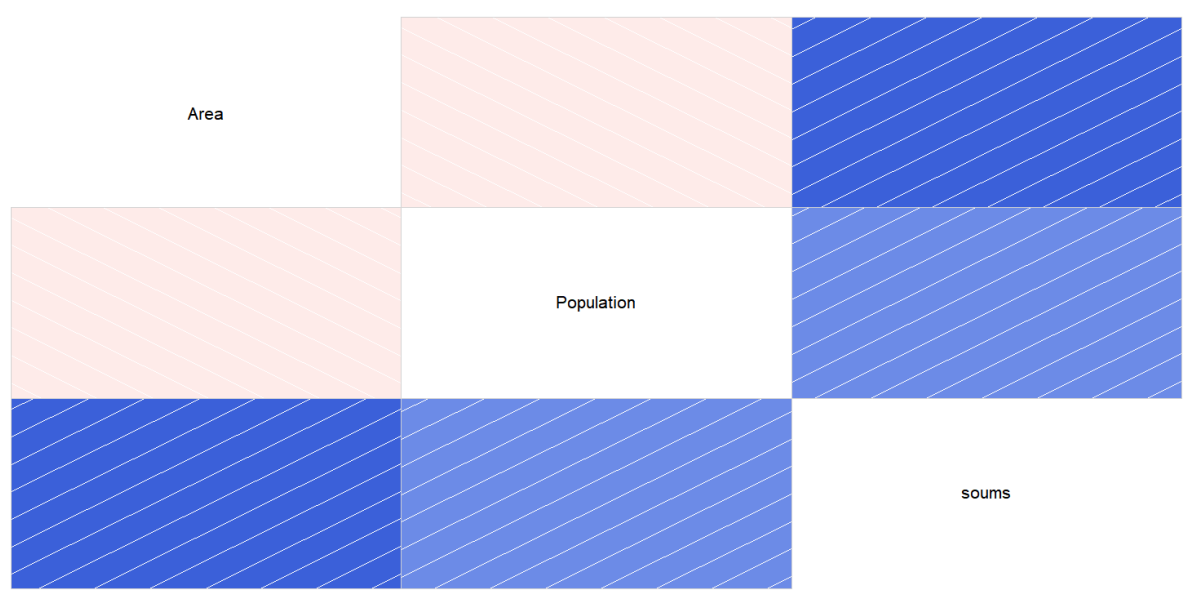

Figure 9. Information about each province in Mongolia big data visualization.

Table 5. Information about each province in Mongolia big data visualization script.

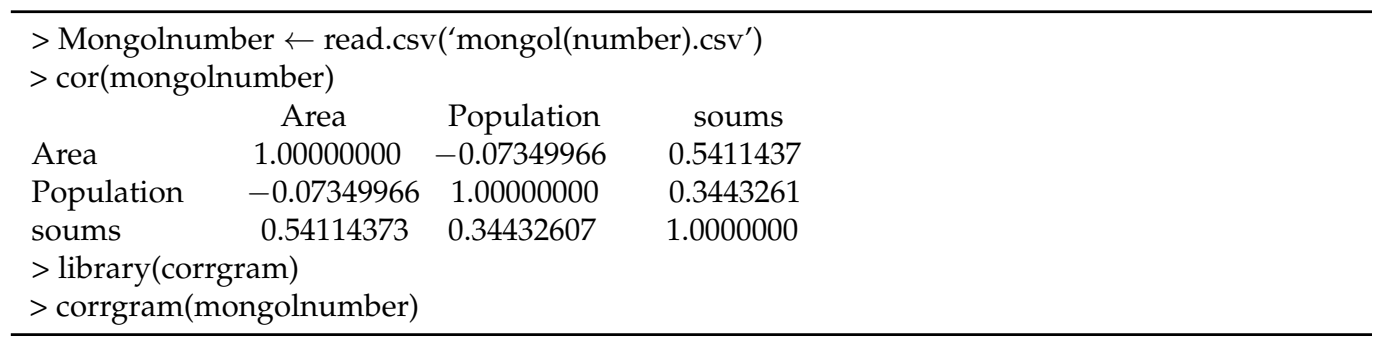

The below graph shows that the significance probability of the correlation for the number of soums according to the area is $0.01 \%$ (positive correlation of 0.54 ). Therefore, since $p<0.05$ or less, the null hypothesis can be rejected, and the alternative hypothesis can be adopted. For the rest, further analysis cannot be performed because the significance level is greater than $p>0.05$.

Then, we will proceed with simple linear regression analysis through the $\mathrm{R}$ programming language to analyze the correlation between the area and the number of soums, which are significantly derived from the correlation analysis.

Figure 10, 1 is the area of each province in Mongolia, 2 is the correlation coefficient between Mongolia's area and population, 3 is the correlation coefficient between Mongolia's area and soums $\left({ }^{*} p<0.05\right), 4$ is the correlation graph between Mongolia's area and population, 5 is Mongolia number of each population in each province, 6 is the correlation coefficient between population and soum, 7 is the correlation graph between Mongolian area and soum, 8 is the correlation graph between Mongolian population and soum, 9 is the number of each soum in each province in Mongolia. 


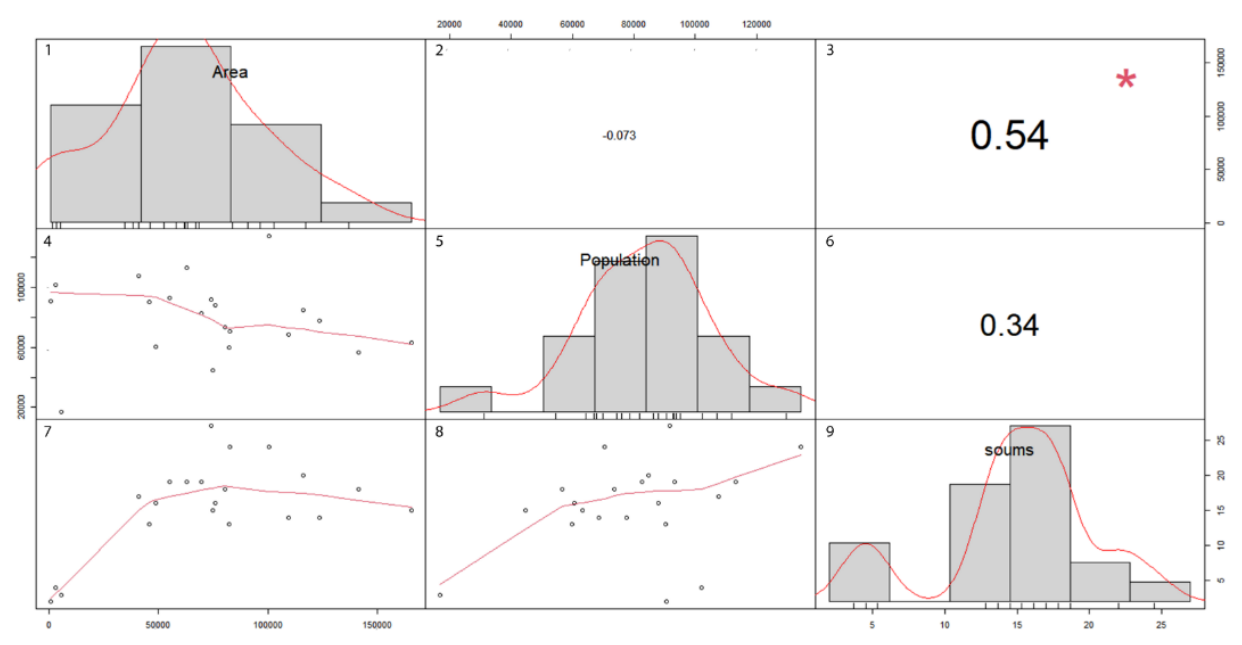

Figure 10. Correlation big data analysis for each province in Mongolia.

Below is the script for Figure 10. Table 6 shows correlation big data analysis for each province in Mongolia's script. Figure 10 is the correlation between the region of Mongolia and the number of soums analyzed to be correlated in Figure 9. These data were visualized through correlation analysis using the R programming language. Table 6 contains the script data of the $\mathrm{R}$ programming language for the correlation big data analysis for each province in Mongolia in Figure 10.

Table 6. Correlation big data analysis for each province in Mongolia's script.

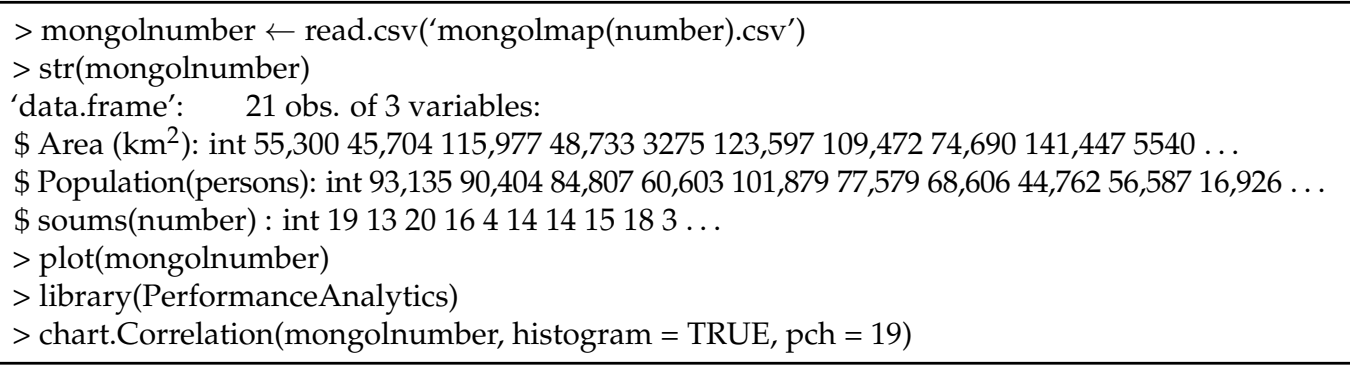

The above graph shows a scatter plot between the area and the number of groups (soums). The red spot is a point showing the correlation between area and soum for 23 soums in Mongolia. As the area increases, it can be seen that the number of groups (soums) increases. Table 7 summarizes the data for the scatterplot for area and soums in Figure 11 and the regression analysis derived using the $\mathrm{R}$ programming language in a table format. Table 7 shows the regression between the area and number of soums.

As a result of the analysis, $\mathrm{F}=7.8618(p<0.05)$, suggesting that this regression implant is suitable. $\mathrm{R}$ (coefficient of determination) has an explanatory power of $25.56 \%$. Since the significance probability according to the $t$ distribution is also lower than 0.05 , we reject the null hypothesis and adopt the alternative hypothesis.

Table 7. Regression between area and number of soums.

\begin{tabular}{cccccc}
\hline- & Estimate & Std. Error & $\begin{array}{c}\mathbf{t}(\mathbf{p}) \\
\operatorname{Pr}(>|\mathbf{t}|)\end{array}$ & $\mathbf{F}(\mathbf{p})$ & $\mathbf{R}^{2}$ \\
\hline (Intercept) & 9.699 & 2.466 & $\begin{array}{c}3.933 \\
0.000892 * * *\end{array}$ & $7.8618^{*}$ & 0.2556 \\
\hline $\begin{array}{c}\text { Regression between area } \\
\text { and number of soums }\end{array}$ & 0.00081 & 2.888 & $\begin{array}{c}2.805 \\
0.011300 *\end{array}$ & - & - \\
\hline${ }^{*} p<0.05 * * * p<0.001$. & & &
\end{tabular}




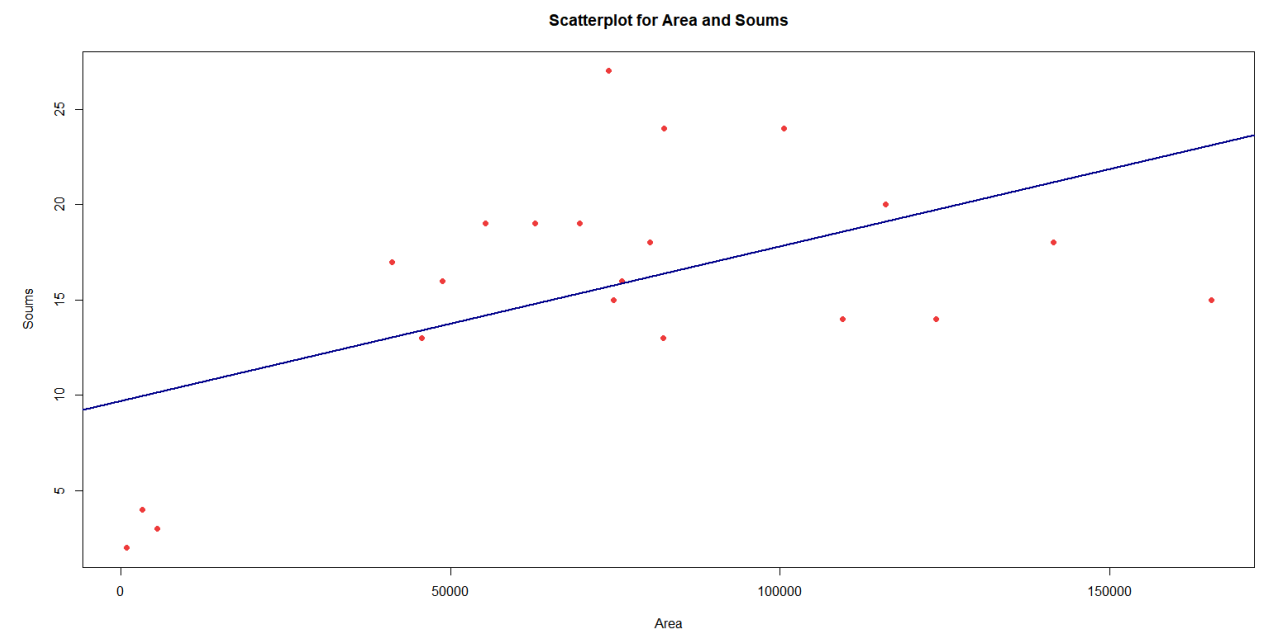

Figure 11. Scatterplot for area and soums.

What is significant in the above analysis is that the number of soums increases as the area increases, so an appropriate approach is needed. In order to reduce the infection of STDs in Mongolia, it is thought that big data systematization of the medical system of soums belonging to each province (aimag) should be accompanied.

Mongolia is divided into three main types of medical services [44,70].

- Basic health services: family hospitals in Ulaanbaatar, hospitals in the province (aimag) or counties (soum).

- Secondary health and medical services: general hospitals in Ulaanbaatar and general hospitals in the province (aimag).

- Three tertiary health services: major hospitals and specialized centers in Ulaanbaatar.

When collecting big data for STDs, it will be divided into 1st, 2nd, and 3rd order to collect big data in stages. If you collect big data in this way, you will be able to analyze STDs information more systematically and accurately.

After collecting big data in this way, a more accurate and comprehensive analysis will be required. Big data comprehensively obtained from basic health services, secondary healthcare services, tertiary healthcare services, and from 21 states (aimag) and 329 counties (soum) is currently statistically analyzed through comprehensive big data analysis. Figure 12 shows the Mongolian STDs comprehensive big data virtualization. Statistical analysis of STDs in Mongolia will be performed, and the overall rate of STDs infection will be lowered.

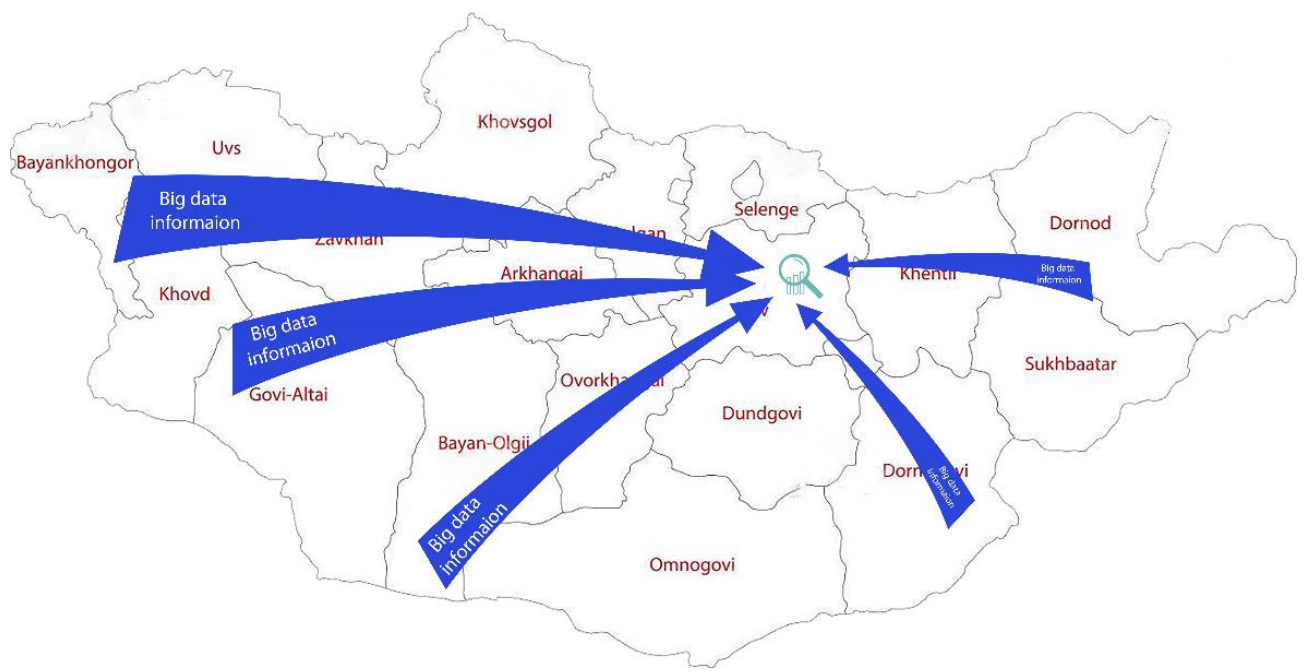

Figure 12. Mongolia STDs comprehensive big data virtualization. 


\section{Inter-Country Big Data Analysis According to HIV, One of the STDs (Focused on Mongolia)}

STDs are recognized as a serious problem in Mongolia, and more than $45 \%$ of infectious diseases are reported to be STDs, but efforts to control it are lacking and data are also lacking [71]. Accordingly, an attempt was made to compare the STDs infection rate according to each aimag in Mongolia, but the above big data analysis could not be carried out because there were no data or there were many insufficient parts. Therefore, according to the 194 countries statistically calculated by the WHO, it was decided to analyze big data to see what kind of data the STDs infection rate has a meaningful relationship with. In addition, there are many types of STDs, such as gonorrhea, chlamydia trachomatis, and syphilis, but since there are no integrated data, we are going to analyze big data based on $\mathrm{HIV}$, which is one of the statistically calculated STDs [72]. The data to be compared here are life expectancy, population density, gender ratio, medical doctor density, educational level, and income level. The results of Pearson's correlation analysis through the R programming language are as follows (Tables 8-13). Tables 8-13 show the STDs (HIV infection) infection and gender ratio, using the $\mathrm{R}$ programming language based on data from the World Health Statistics (2021) and Human Development (2021). The correlation analysis of life expectancy, medical expenses (more than $25 \%$ of household expenditure), population density, medical doctor density, and education index is presented in table format.

Table 8. STDs (HIV infection) infection rate according to gender ratio.

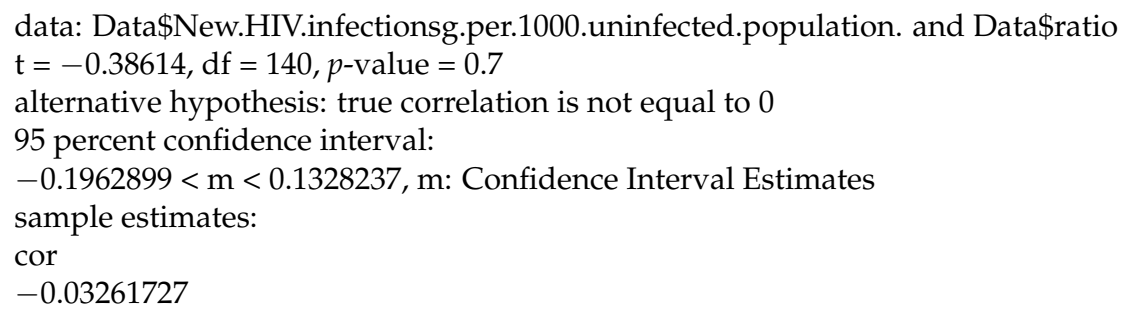

Table 9. STDs (HIV infection) infection rate according to life expectancy.

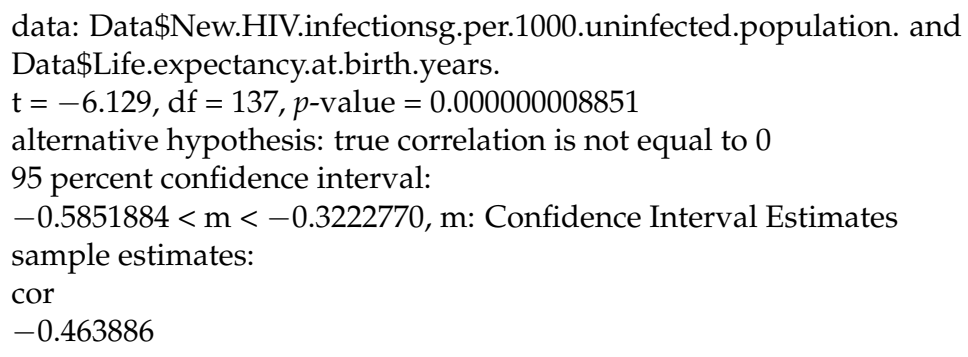

Table 10. STDs (HIV infection) infection rate according to medical expenses (more than $25 \%$ of household expenditure).

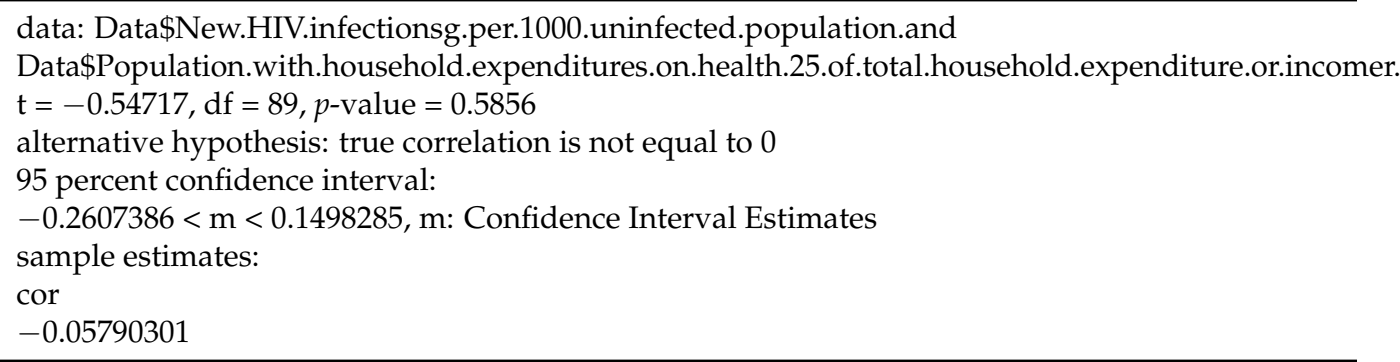


Table 11. STDs (HIV infection) infection rate according to population density.

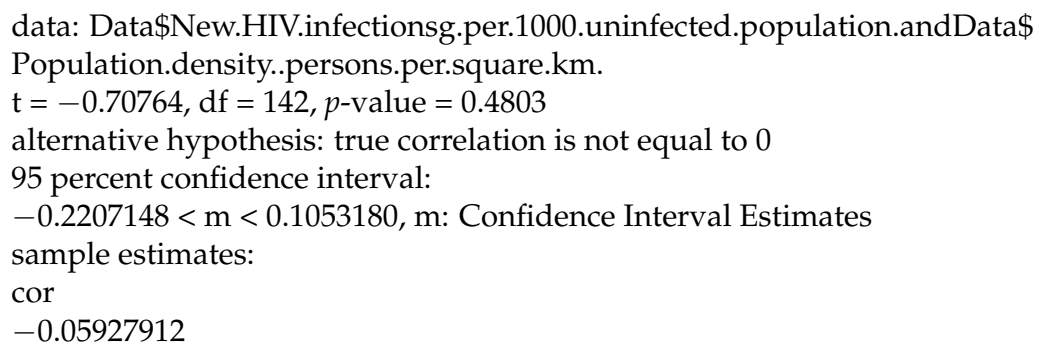

Table 12. STDs (HIV infection) infection rate according to medical doctor density.

data: Data\$New.HIV.infectionsg..per.1000.uninfected.population.and

Data\$Density.of.medical.doctorsx..per.10.000.population.

$\mathrm{t}=-3.4625, \mathrm{df}=141, p$-value $=0.0007088$

alternative hypothesis: true correlation is not equal to 0

95 percent confidence interval:

$-0.4245757<\mathrm{m}<-0.1213652, \mathrm{~m}$ : Confidence Interval Estimates

sample estimates:

cor

$-0.2799369$

Table 13. STDs (HIV infection) infection rate according to education index.

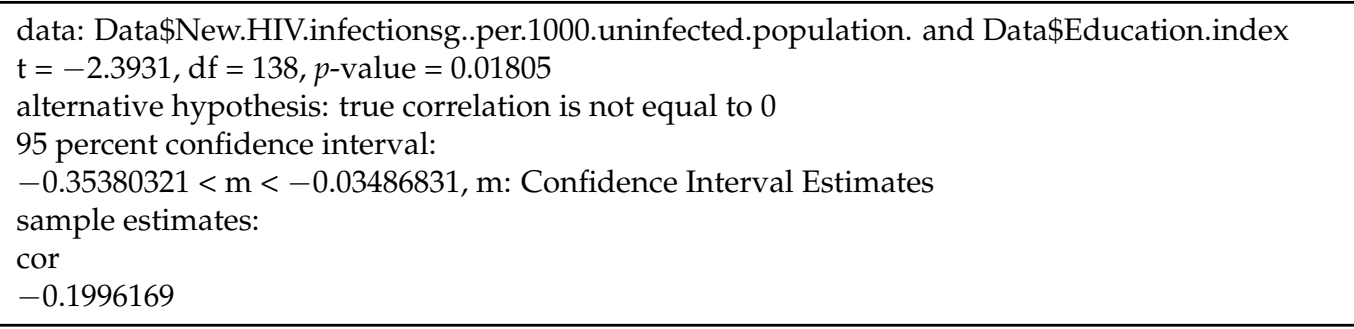

The graph above is a negative correlation of -0.46 for the life expectancy according to the HIV infection rate during STDs. Since the significance probability according to the $\mathrm{t}$-distribution is also less than 0.05 ( $p$-value $=0.000000008851,{ }^{*}$ means $\left.p<0.05\right)$, the null hypothesis is rejected, and the alternative hypothesis is adopted. The above graph that analyzed the two significant correlations through the $\mathrm{R}$ programming language is shown in Figure 13.

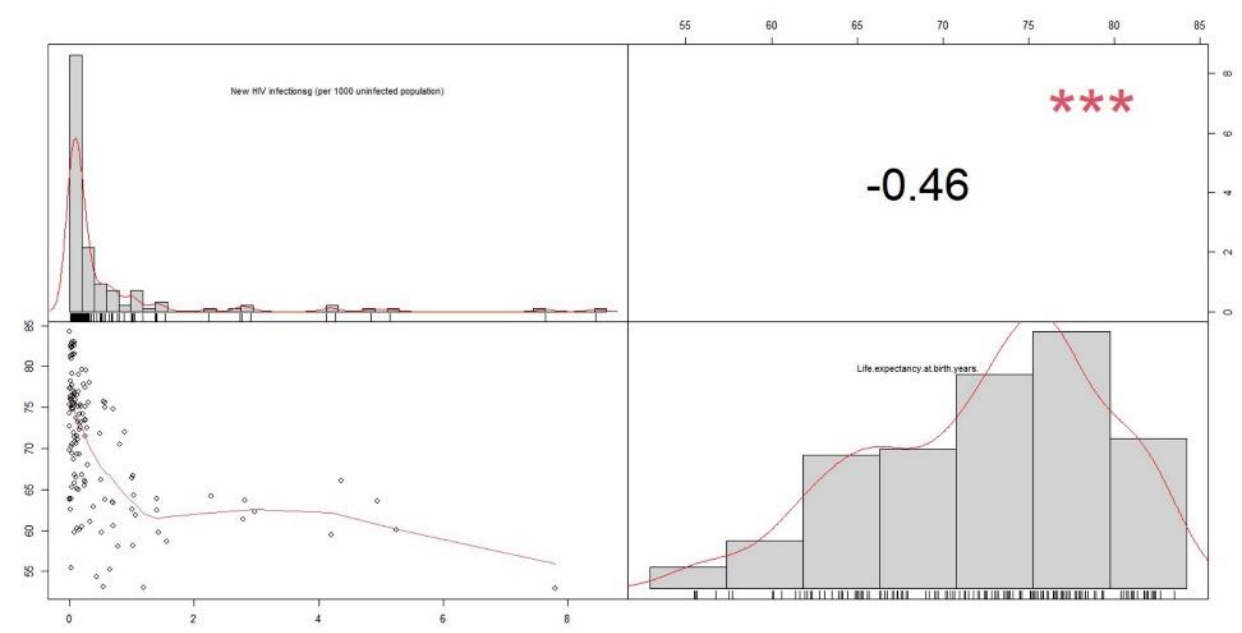

Figure 13. Big data analysis of correlation between life expectancy according to STDs (HIV infection) rate. 
In the above correlation analysis, a statistically significant correlation $(p<0.05$, *** means $p<0.001$ ) was the HIV infection rate according to the density of medical doctors and the HIV infection rate according to the educational level. The graph that analyzed the two significant correlations through the R programming language is shown in Figure 13.

Figure 14 shows a big data analysis of the correlation between the medical doctor density according to the HIV infection rate during STDs (negative correlation of -0.28 ), Since the significance probability according to the t-distribution is also less than 0.05 ( $p$-value $=0.0007088)$, the null hypothesis is rejected, and the alternative hypothesis is adopted. Medical doctor density here refers to the number of medical doctors per 10,000 population.

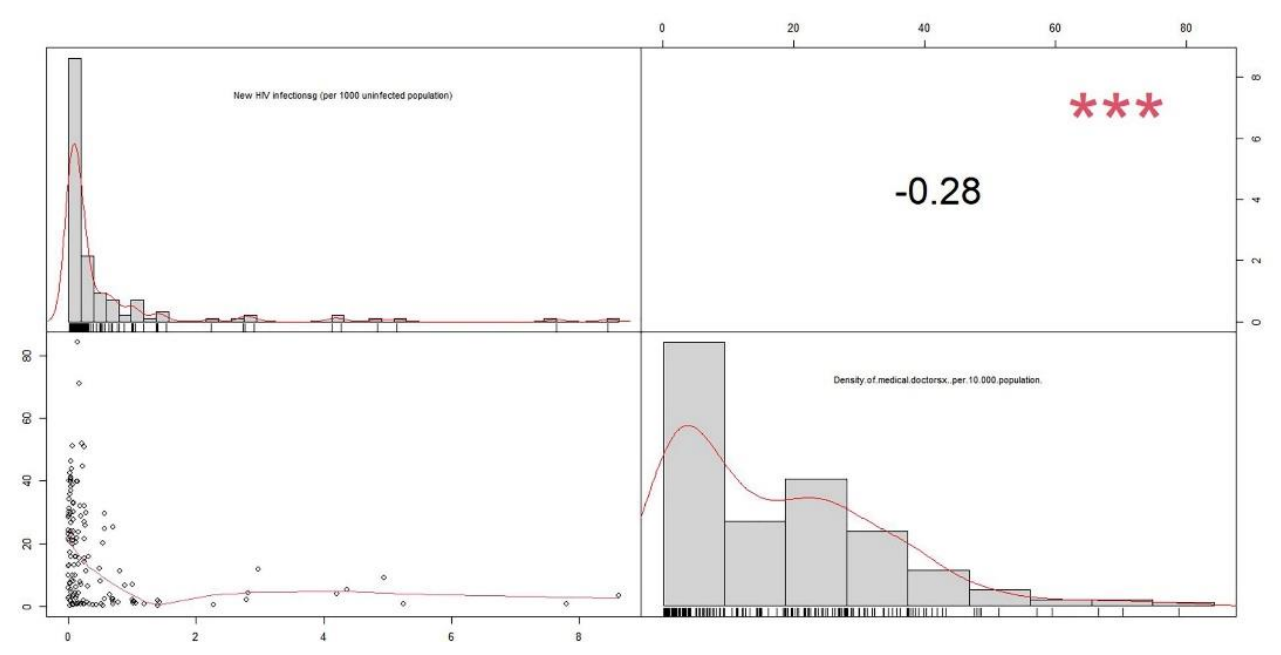

Figure 14. Big data analysis of correlation between medical doctor density according to STDs (HIV infection) rate.

Figure 15 shows a negative correlation of -0.20 for the education index according to the HIV infection rate during STDs. Since the significance probability according to the $\mathrm{t}$-distribution is also less than 0.05 ( $p$-value $=0.01805,{ }^{*}$ means $p<0.05$ ), the null hypothesis is rejected, and the alternative hypothesis is adopted. Here, the educational relationship is derived according to the following formula [73].

$$
\text { Education Index : } \frac{\text { EYS }}{18}+\frac{\text { MYS }}{15} / 2
$$

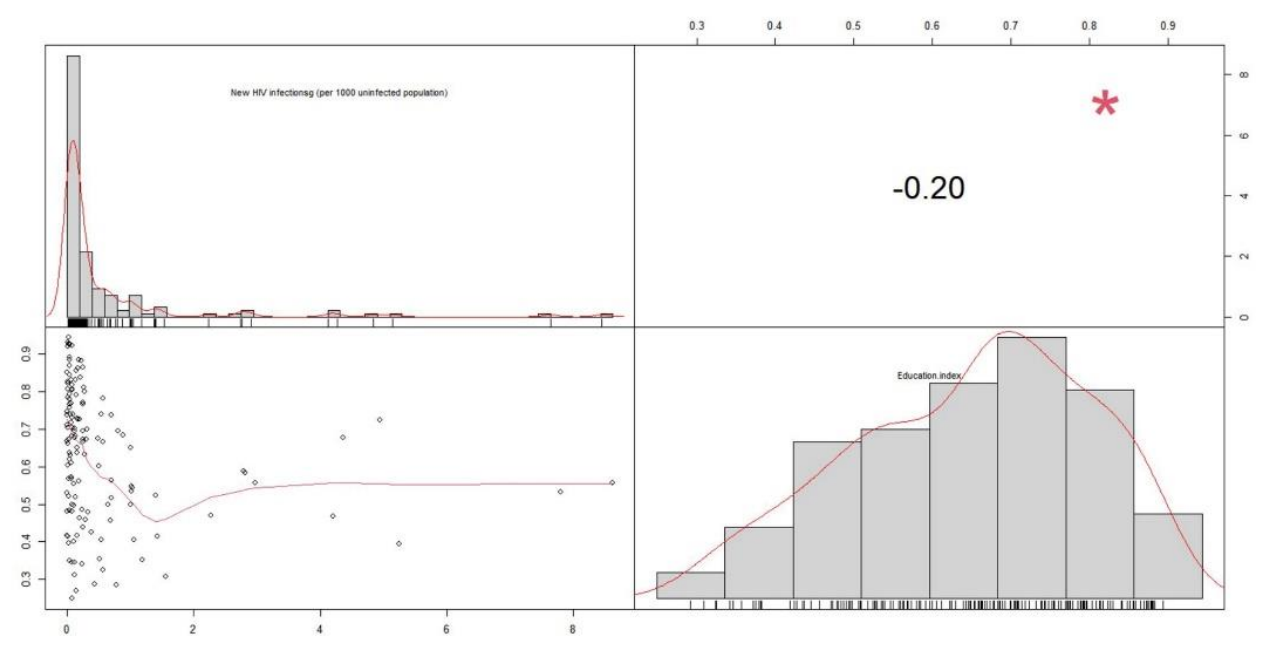

Figure 15. Education index correlation big data analysis according to STDs (HIV infection) rate. 
EYS (Expected Years Schooling): The estimated length of education is a calculation of the number of years a student is expected to attend school or college. In most countries, a master's degree represents the highest level of education attainable, and earning a master's degree reflects 18 years of education [74].

MYS (Mean Years of Schooling): The average number of years of education is calculated by calculating the average number of years of education actually received by students over the age of 25. It is based on the education level of the population converted to years of education based on the theoretical duration of each level of education received [75].

Based on this, we will proceed with regression analysis through the $\mathrm{R}$ programming language.

The Table 14 is a regression analysis of STDs (HIV infection) and life expectancy. The analysis result $\mathrm{F}=37.56(p<0.001)$ suggests that this regression implant is suitable. $\mathrm{R}$ (coefficient of determination) has an explanatory power of $21.52 \%$. Since the significance probability according to the $t$ distribution is also lower than 0.001 , we reject the null hypothesis and adopt the alternative hypothesis.

Table 14. Regression between STDs (HIV infection) and life expectancy.

\begin{tabular}{|c|c|c|c|c|c|}
\hline- & Estimate & Std. Error & $\begin{array}{c}t(p) \\
\operatorname{Pr}(>|t|)\end{array}$ & $F(p)$ & $\mathbf{R}^{2}$ \\
\hline (Intercept) & 72.4708 & 0.6048 & $\begin{array}{c}111.845 \\
<0.0000000000000002^{* * *}\end{array}$ & $37.56^{* * *}$ & 0.2152 \\
\hline STDs (HIV infection) & -3.2737 & 0.5341 & $\begin{array}{c}-6.129 \\
0.00000000885^{* * *}\end{array}$ & - & - \\
\hline
\end{tabular}

$\overline{* * *} p<0.001$.

The Figure 16 is a scatter plot graph of STDs (HIV infection) and life expectancy at birth years. It can be seen that as the STDs (HIV infections) increase, the life expectancy decreases.

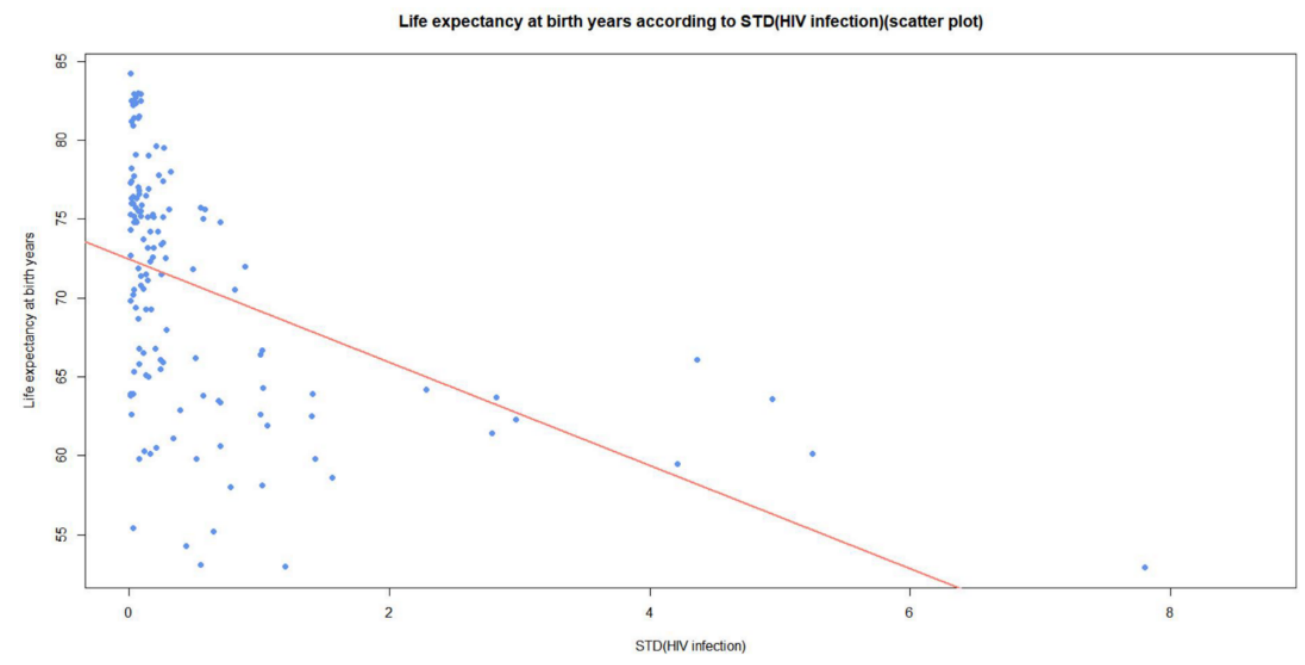

Figure 16. Scatterplot for STDs (HIV infection) and life expectancy at birth years.

It is the result of the medical doctor density regression analysis according to the HIV infection rate among STDs. Table 14 shows regression between STDs (HIV infection) and density of medical doctors.

Table 15 shows the correlation analysis between STDs (HIV infection) and density of medical doctors using the $\mathrm{R}$ programming language based on the data of World Health Statistics (2021) published by the WHO. 
Table 15. Regression between STDs (HIV infection) and density of medical doctors.

\begin{tabular}{cccccc}
\hline & Estimate & Std. Error & $\begin{array}{c}\mathbf{t}(\mathbf{p}) \\
\operatorname{Pr}(>|\mathbf{t}|)\end{array}$ & $\mathbf{F}(\mathbf{p})$ & $\mathbf{R}^{2}$ \\
\hline (Intercept) & 18.570 & 1.430 & $<0.0000000000000002 * * *$ & $11.09 *$ & 0.07183 \\
\hline STDs (HIV infection) & -3.557 & 1.027 & $\begin{array}{c}12.987 \\
0.000709 * * *\end{array}$ & - & - \\
\hline
\end{tabular}

${ }^{*} p<0.05,{ }^{* * *} p<0.001$.

The analysis result $\mathrm{F}=11.09(p<0.05)$, suggesting that this regression implant is suitable. R (coefficient of determination) has an explanatory power of $11.09 \%$. Since the significance probability according to the $t$ distribution is also lower than 0.05 , we reject the null hypothesis and adopt the alternative hypothesis.

The Figure 17 is a scatter plot graph of STDs (HIV infection) and density of medical doctors. It can be seen that as the STDs (HIV infections) increase, the density medical doctors decreases.

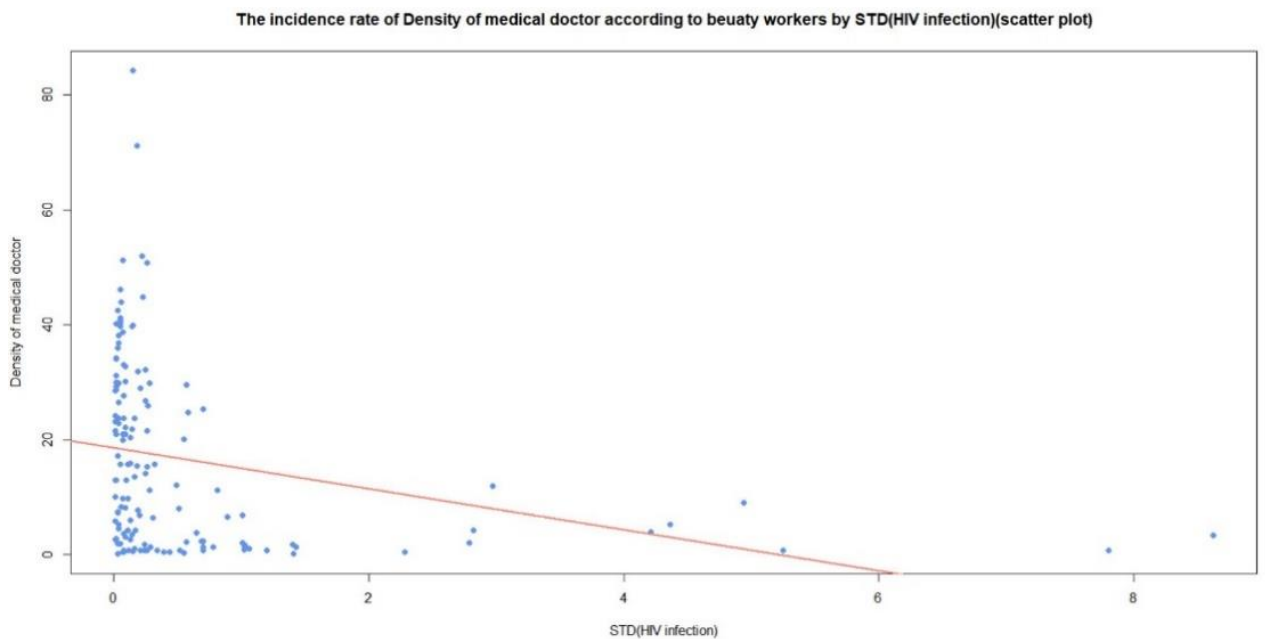

Figure 17. Scatterplot for STDs (HIV infection) and density of medical doctors.

Next are the results of the education index regression analysis according to the HIV infection rate belonging to STDs. Table 15 shows the regression between STDs (HIV infection) and education. Figure 16 shows a scatterplot for STDs (HIV infection) and education.

Table 16 shows the correlation analysis between STDs (infection) and education using the R programming language based on the data of Human Development (2021).

Table 16. Regression between STDs (HIV infection) and education.

\begin{tabular}{|c|c|c|c|c|c|}
\hline- & Estimate & Std. Error & $\begin{array}{c}t(p) \\
\operatorname{Pr}(>|t|)\end{array}$ & $F(p)$ & $\mathbf{R}^{2}$ \\
\hline (Intercept) & 0.64960 & 0.01606 & $\begin{array}{c}40.439 \\
<0.0000000000000002 * * *\end{array}$ & $5.727^{*}$ & 0.03289 \\
\hline STDs (HIV infection) & -0.02733 & 0.01142 & $\begin{array}{l}-2.393 \\
0.181 *\end{array}$ & - & - \\
\hline
\end{tabular}

${ }^{*} p<0.05,{ }^{* * *} p<0.001$.

The analysis result $\mathrm{F}=5.727(p<0.05)$ suggests that this regression implant is suitable $\mathrm{R}$ (coefficient of determination) has an explanatory power of $11.09 \%$. Since the significance probability according to the $t$ distribution is also lower than 0.05 , we reject the null hypothesis and adopt the alternative hypothesis. 
The Figure 18 is a scatterplot of STDs (HIV infection) and education. It can be seen that the education index decreases as the STDs (HIV infection) increase. Based on the above analysis results, it can be seen that the educational level and the density of doctors decrease as STDs (HIV infection) increase. Therefore, it can be seen that in order to reduce the infection of STDs (HIV infection), it is necessary to increase the educational level and the density of doctors. Here, analysis and statistics on HIV infection, which is one type of STD, were simply conducted. If statistics on other types of STDs are also available, a new analysis will be needed.

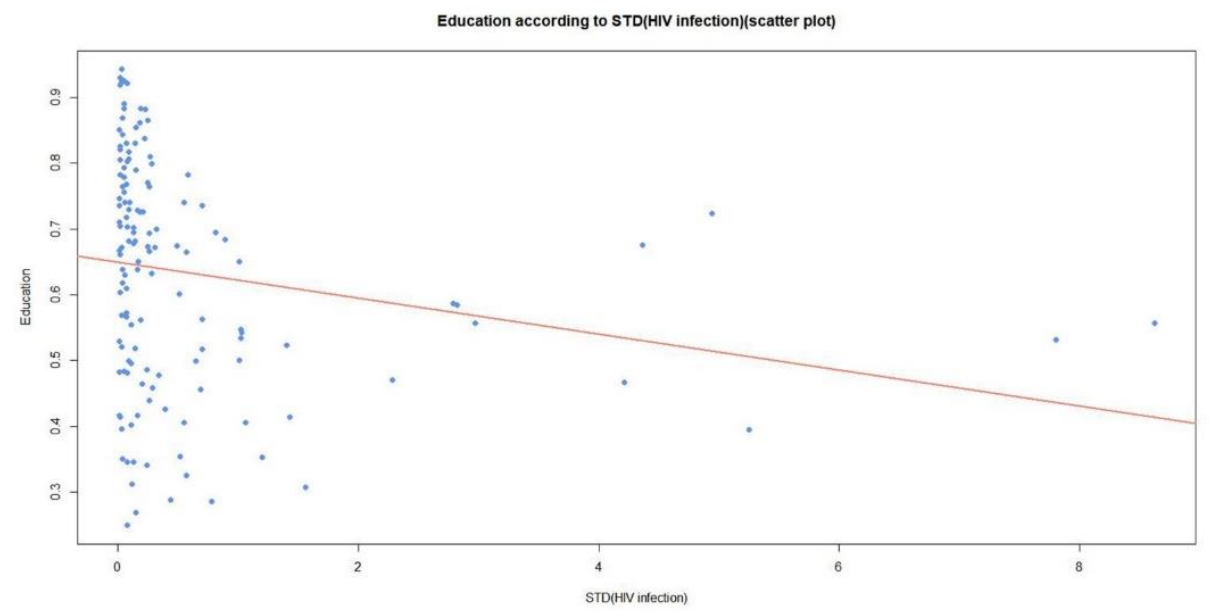

Figure 18. Scatterplot for STDs (HIV infection) and education.

\section{Conclusions and Limitations}

Based on the above study results, we will investigate the infection of STDs. Figure 19 and Table 17 show the number of people infected with STDs around the world every year, which is analyzed using the R programming language. Table 17 compares statistics for curable STDs and incurable STDs.

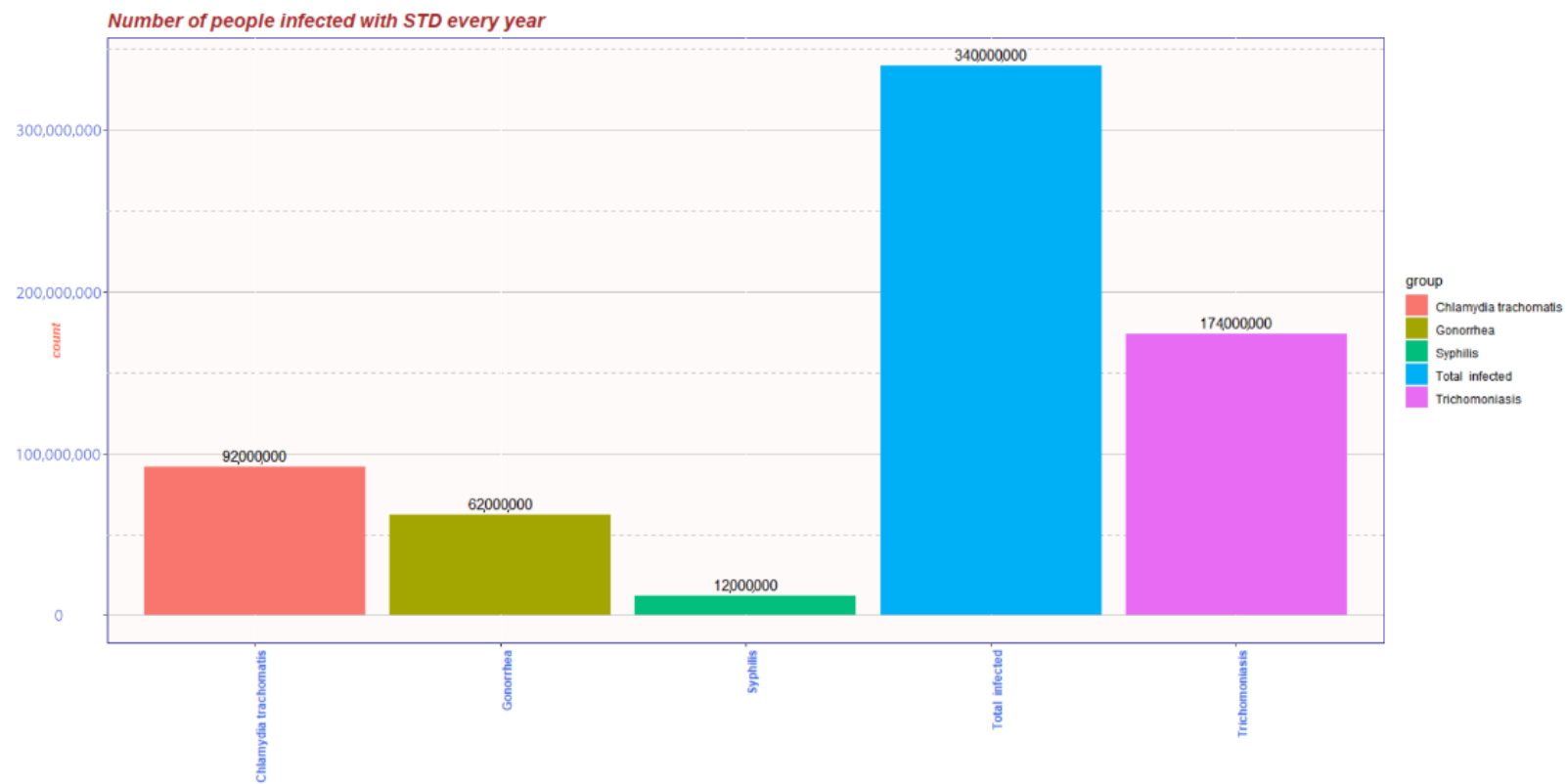

Figure 19. Virtualization of the number of people infected with STDs every year using the R programming language. 
Table 17. Curable disease and incurable disease (STDs).

\begin{tabular}{cc}
\hline Classification & Disease \\
\hline Curable STDs & Gonorrhea \\
& Chlamydia trachomatis \\
Syphilis \\
Tncurable STDs & Trichomonas vaginalis infections \\
& Human Immunodeficiency Virus (HIV) \\
& Herpes Simplex Viruses (Herpes Simplex Virus, HSV) \\
Human Papillomavirus (HPV) \\
Hepatitis B virus
\end{tabular}

In Mongolia, due to the influence of religion and past nomadic life, the current rate of STDs infection is relatively high compared to the population. Due to the lack of treatment technology and information, the actual situation is not well understood. In fact, even if they are infected with STDs, many people live without knowing that they are infected. In addition, more than half of the population is concentrated in the capital, and the population density is quite high in the capital. By big data analysis, we can accurately identify infected people in Mongolia with a relatively high rate of STDs. It will be possible to bear significant costs for the healthcare field of individuals and society.

Limitations exist to this paper: first of all, securing sufficient accessibility to big data. If the public does not have sufficient access to big data before grasping the information of STDs through the collection of big data, they will face great difficulties in collecting data. Therefore, in order to secure accessibility to the population's big data, education on big data will be needed first.

Second, the use of collected big data is whether it will be used for public interest purposes. Since the collected big data contain a lot of very sensitive information, it must be used only for public interest purposes. If used for the purpose of pursuing private interests, it would have a large negative impact on the health system of the country.

Lastly, through the data analyzed with big data, it will be necessary to actively link the country, data analysis institutions, and healthcare institutions. If there is no interconnection in this part, it will only be a very fragmentary analysis.

Author Contributions: All listed authors meet the ICMJE criteria and all who meet the four criteria are identified as authors. We attest that all authors contributed significantly to the creation of this manuscript, each having fulfilled criteria as established by the ICMJE. All authors have read and agreed to the published version of the manuscript.

Funding: This research received no external funding.

Conflicts of Interest: The authors declare no conflict of interest.

\author{
Abbreviations \\ STDs Sexually Transmitted Diseases \\ WHO World Health Organization \\ HIV Human Immunodeficiency Virus \\ HSV Herpes Simplex Virus \\ HPV Human Papillomavirus \\ AIDS Acquired Immune Deficiency Syndrome \\ STI Sexually Transmitted Infection \\ STIs Sexually Transmitted Infections \\ OECD Organization for Economic Co-operation and Development \\ GDP Gross Domestic Product \\ FGP Family Group Practice \\ DNA Deoxyribonucleic Acid \\ HBV Hepatitis B Virus \\ HIF Health Insurance Fund
}




\section{References}

1. Multidisciplinary Digital Publishing Institute. Available online: https://www.mdpi.com/journal/biomedicines/special_issues/ bioinformatics_biomedicine (accessed on 11 August 2021).

2. Workowski, K.A.; Berman, S.M. Sexually Transmitted Diseases Treatment Guidelines, 2006. MMWR Recomm. Rep. 2006, 55, 1-94.

3. Workowski, K.A.; Bolan, G.A. Sexually Transmitted Diseases Treatment Guidelines, 2015. MMWR Recomm. Rep. 2015, 64, 1-140.

4. Lee, I.-S. Historical Changes and the Present Situation of Sexually Transmitted Diseases. J. Korean Med. Assoc. 2008, 51, 868-874. [CrossRef]

5. UNAIDS. Force for Change: World AIDS Campaign with Young People. UNAIDS 1998 Theme; UNAIDS: Geneva, Switzerland, 1998; pp. 8-9.

6. WHO. Global Strategy for Prevention and Control of Sexually Transmitted Infections (2006-2015); WHO: Geneva, Switzerland, 2017; pp. 1-69.

7. Workowski, K.A. Centers for Disease Control and Prevention Sexually Transmitted Diseases Treatment Guidelines. Clin. Infect. Dis. 2015, 61, 759-762. [CrossRef]

8. Saag, M.S. HIV Infection-Screening, Diagnosis, and Treatment. N. Engl. J. Med. 2021, 384, 2131-2143. [CrossRef]

9. Williamson, D.A.; Chen, M.Y. Emerging and Reemerging Sexually Transmitted Infections. N. Engl. J. Med. 2020, 382, $2023-2032$. [CrossRef]

10. Ağaçfidan, A.; Kohl, P. Sexually transmitted diseases (STDs) in the world. FEMS Immunol. Med. Microbiol. 1999, 24, 431-435. [CrossRef]

11. Ryan, K.J.; Ray, C.G. Sherris Medical Microbiology, 4th ed.; McGawHill: New York, NY, USA, 2004.

12. Detels, R.; Green, A.M.; Klausner, J.D.; Katzenstein, D.; Gaydos, C.; Handsfield, H.H.; Pequegnat, W.; Mayer, K.; Hartwell, T.D.; Quinn, T.C. The incidence and correlates of symptomatic and asymptomatic Chlamydia trachomatis and Neisseria gonorrhoeae infections in selected populations in five countries. Sex. Transm. Dis. 2011, 38, 503-509. [CrossRef]

13. Davies, B.; Turner, K.M.E.; Frølund, M.; Ward, H.; May, M.T.; Rasmussen, S.; Benfield, T.; Westh, H.; Danish Chlamydia Study Group. Risk of reproductive complications following chlamydia testing: A population-based retrospective cohort study in Denmark. Lancet Infect. Dis. 2016, 16, 1057-1064. [CrossRef]

14. Wolff, K.; Goldsmith, S.K.L.; Gilchrest, B.; Paller, A.S.; Leffell, D. Fitzpatrick's Dermatology in General Medicine, 7th ed.; McGraw-Hill: New York, NY, USA, 2008; pp. 1955-1977.

15. Jones, H.W.; Georgeanna, S. Novak's Textbook of Gynecology, 10th ed.; Williams \& Wilkins: Philadelphia, PA, USA, 1981.

16. Cho, K.S.; Lee, D.G.; Park, Y.D.; Shin, S.C.; Lee, S.H.; Roh, H.J. Analysis of Otorhinolaryngologic disease in patients with human immunodeficiency virus infection. Korean J. Otorhinolaryngol. Head Neck Surg. 2009, 52, 506-511. [CrossRef]

17. Barcelona, D.; Laski, L.; Gerdits, C. Universal sexuality education in mongolia: Educating today to protect tomorrow. Soc. Behav. Sci. Res. 2002, 12, 1-39.

18. Cartagena, R.G.; Veugelers, P.J.; Kipp, W.; Magigav, K.; Laing, L.M. Effectiveness of an HIV prevention program for secondary school students in Mongolia. J. Adolesc. Health 2006, 39, 925. [CrossRef]

19. Ebright, J.R.; Altantseteseg, T.; Oyungerel, R. Emerging infectious diseases in Mongolia. J. Emerg. Infect. Dis. 2003, 9, 1509-1515. [CrossRef] [PubMed]

20. Kipp, W.; Sodnompil, T.; Tuya, M.; Erdenchimeg, E.; Nymadawa, P. Reproductive health in Mongolia: Results from three provinces and one urban district. Trop. Dr. 2002, 32, 159-162. [CrossRef] [PubMed]

21. Bayasgalan, G.; Naranbat, D.; Tsedmaa, B.; Tsogmaa, B.; Sukhee, D.; Amarjargal, O.; Lhagvasuren, T.; Radnaabazar, J.; Rowe, P.J Clinical patterns and major causes of infertility in Mongolia. J. Obstet. Gynaecol. Res. 2004, 30, 386-393. [CrossRef]

22. UNAIDS. Report on the Global HIV/AIDS Epidemics; UNAIDS: Geneva, Switzerland, 2000.

23. Peer Educator Training Manual; Directorate of Medical Services, Ministry of Health: Ulaanbaatar, Mongolia, 2004.

24. Smith, C.J. Social geography of sexually transmitted diseases in China: Exploring the role of migration and urbanization. Asia Pac. Viewp. 2005, 46, 65-80. [CrossRef]

25. Netesov, S.V.; Conrad, J.L. Emerging infectious diseases in Russia 1990-1999. Emerg. Infect. Dis. 2001, 7, 1-5. [CrossRef]

26. New Horizons: The Newsletter of the UN in Mongolia; United Nations: New York, NY, USA, 2003; Volume 4, pp. 4-10.

27. Grassley, N.; Garnett, G. The future of the HIV pandemic. Bull. World Health Organ. 2005, 83, 378-383.

28. Chayavichitsilp, P.; Buckwalter, J.V.; Krakowski, A.C.; Friedlander, S.F. Herpes simplex. Pediatr. Rev. 2009, 30, 119-129. [CrossRef] [PubMed]

29. zur Hausen, H. Perspectives of contemporary papillomavirus research. Vaccine 2006, 24, iii-iv. [CrossRef] [PubMed]

30. World Health Organization. Available online: https://www.who.int/en/news-room/fact-sheets/detail/hepatitis-b (accessed on 11 August 2021).

31. Adler, M.W. Sexually transmitted diseases control in developing countries. Sex. Transm. Infect. 1996, 72, 83-88. [CrossRef] [PubMed]

32. Bhuiyan, B.U.; Rahman, M.; Miah, M.R.; Nahar, S.; Islam, N.; Ahmed, M.; Rahman, K.M.; Albert, M.J. Antimicrobial susceptibilities and plasmid contents of Neisseria gonorrhoeae isolates from commercial sex workers in Dhaka, Bangladesh: Emergence of high-level resistance to ciprofloxacin. J. Clin. Microbiol. 1999, 37, 1130-1136. [CrossRef]

33. Apalata, T.; Zimba, T.F.; Sturm, W.A.; Moodley, P.; Nabi, M.H.; Hawlader, M.D.H. Antimicrobial susceptibility profile of Neisseria gonorrhoeae isolated from patients attending a STD facility in Maputo, Mozambique. Sex. Transm. Dis. 2009, 36, 341-343. [CrossRef] 
34. Farabi, T.J.; Jahangir, Y.T.; Clara, A.A.; Nabi, M.H.; Hawlader, M.D.H. Sexually Transmitted Infections among Street, Hotel, and Residence-Based Female Sex Workers in Dhaka, Bangladesh: Prevalence from Three HIV/STI Drop-in-Centers. Sexes 2021, 2, 69-78. [CrossRef]

35. Namjil, T. Family Manner E Tradition in Mogolids; Minseokwon: Seoul, Korea, 2007.

36. Kim, G.S. Mongolia Cultural History; Tongmoonseon: Seoul, Korea, 1991.

37. WHO. World Health Statistics 2021: Annex 2; WHO: Geneva, Switzerland, 2021.

38. UNDP. Human Development Reports 2020; UNDP: New York, NY, USA, 2020.

39. Lee, J.-H.; Je, M.-G.; Jo, M.-J.; Son, H.-S. Trends in the use of big data in the health care field. Korea Inst. Inf. Commun. Eng. 2014, $32,63-75$.

40. Yoo, W.-K. Mongolian Health Care System and the Health Status of Mongolian People. Korean Assoc. Mong. Stud. $2010,1,327-341$.

41. KHIDI. Guide to Korean Medical Advancement to Mongolia; KHIDI: Chungcheongbuk, Korea, 2014; pp. 1-186.

42. WHO. Health Financing Strategy for the Asia Pacific Region (2010-2015); WHO: Geneva, Switzerland, 2009; pp. 1-43.

43. WHO and Mongolian Ministry of Health. Health Service Delivery Profile; WHO and Mongolian Ministry of Health: Ulaanbatar, Mongolia, 2012; pp. 4-5.

44. Central Intelligence Agency. Available online: https://www.cia.gov/ (accessed on 11 August 2021).

45. Nam, E.-W. Hospital Management; Shinkwang: Seoul, Korea, 2002.

46. A Study on the Criteria for Accreditation of Tertiary Care Institutions; NECA: Hillside, NJ, USA, 1995; p. 12.

47. Kim, G.-H. Measures to establish functions of medical institutions to establish a medical delivery system. Stud. Health Insur. Rev. Assess. Serv. 2015, 9, 1-11.

48. Health Indicators. 2018. Available online: http://www.hdc.gov.mn/media/uploads/2019-11/2018eng.pdf (accessed on 5 August 2021).

49. WHO. World Health Statistics; WHO: Geneva, Switzerland, 2011. Available online: https://reliefweb.int/report/world/worldhealth-statistics-2011?gclid=EAIaIQobChMIorSj7JzE9AIVl1VgCh3kxwOKEAAYASAAEgJhw_D_BwE (accessed on 3 August 2021).

50. Lee, P.-R. Korean Intellectuals' Recognition on Mongolia in the First Half of the 20th Century 3, Misunderstanding and Prejudice about Mongolia and its Culture. Korean Assoc. Cent. Asian Stud. 2014, 17, 195-228.

51. June, M.K.; Choi, J.Y.; Jeong, W.Y.; Seong, H.; Kim, S.W.; Kim, W.J.; Choi, H.J.; Kim, M.J.; Woo, J.H.; Kim, Y.J.; et al. Mode of Human Immunodeficiency Virus Transmission in Korea: The Korea HIV/AIDS Cohort Study. Korean J. Med. 2018, 93, $379-386$.

52. Lee, S.-H.; Kim, S.-J.; Lee, Y.-J.; Kim, S.-Y. Knowledge and Actual Condition of Sexually-Transmitted Disease in Mongolian. J. Korean Public Health Nurs. 2011, 25, 255-265.

53. Mavragani, A.; Ochoa, G. Infoveillance of infectious diseases in USA: STDs, tuberculosis, and hepatitis. J. Big Data 2018, 5, 30. [CrossRef]

54. Mavragani, A.; Sampri, A.; Sypsa, K.; Tsagarakis, K.P. Integrating Smart Health in the US Health Care system: Infodemiology Study of asthma monitoring in the Google era. JMIR Public Health Surveill. 2018, 4, e24. [CrossRef]

55. Baseman, J.G.; Revere, D.; Painter, I. Big data in the era of health information exchanges: Challenges and opportunities for public health. Informatics 2017, 4, 39. [CrossRef]

56. Zhou, X.; Ye, J.; Feng, Y. Tuberculosis surveillance by analyzing google trends. IEEE Trans. Biomed. Eng. 2011, 58, 2247-2254. [CrossRef]

57. Johnson, A.K.; Mehta, S.D. A comparison of internet search trends and sexually transmitted infection rates using google trends. Sex. Transm. Dis. 2014, 41, 61-63. [CrossRef]

58. Rohart, F.; Milinovich, G.J.; Avril, S.M.R.; Lê Cao, K.-A.; Tong, S.; Hu, W. Disease surveillance based on Internet-based linear models: An Australian case study of previously unmodeled infection diseases. Sci. Rep. 2016, 6, 38522. [CrossRef]

59. Mavragani, A.; Ochoa, G. Forecasting AIDS prevalence in the united states using online search traffic data. J. Big Data 2018, 5, 17. [CrossRef]

60. Mavragani, A.; Sypsa, K.; Sampri, A.; Tsagarakis, K.P. Quantifying the UK online interest in substances of the EU watch list for water monitoring: Diclofenac, estradiol, and the macrolide antibiotics. Water 2016, 8, 542. [CrossRef]

61. Gahr, M.; Uzelac, Z.; Zeiss, R.; Connemann, B.J.; Lang, D.; Schönfeldt-Lecuona, C. Linking annual prescription volume of antidepressants to corresponding web search query data: A possible proxy for medical prescription behavior? J. Clin. Psychopharmacol. 2015, 35, 681-685. [CrossRef] [PubMed]

62. Song, T.; Song, J. Social Big Data Analysis and Utilization Methodologies-With Special Reference to Forecasting the Dangers of Sexting in Korea Using Social Big Data. Available online: http:/ / repository.kihasa.re.kr/bitstream/201002/15079/1/\%EC\%9B\%

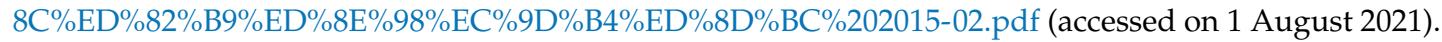

63. University of Mongolia. Students and Graduates Department. Available online: https:/ /www.student.num.mn/p=6999 (accessed on 25 September 2021).

64. Yu, W.S. The tradition and present situation of pastoral nomadism in the Mongolian plateau. J. Hum. Stud. 2012, 67, 349-380.

65. Shin, H.D. Culture Shock! Mongolia: A Guide to Customs and Etiquette; Whistler: Seoul, Korea, 2005; pp. 121-130.

66. Kim, J.; Cha, N.H. Validity and Reliability of the Sexual Knowledge and Sexual Attitude for Mongolian University Students. J. Converg. Cult. Technol. 2021, 7, 139-148.

67. Kang, H.-J. National-Level Use of Health Care Big Data and Its Policy Implications. Health Welf. Policy Forum 2016, $238,55-71$.

68. Korea Foundation. Korea Foundation for International Healthcare. 2011. Available online: https://www.who.int/pmnch/about/ members/database/kofih/en/ (accessed on 3 August 2021). 
69. Kim, G.; Cho, S. Factors Influencing Sexually Transmitted Diseases Prevention and Screening Intentions (Behaviors) among Young Koreans in their 20s Applying Extended Health Belief Model. J. Public Relat. 2020, 24, 92-126.

70. Kim, H.; Lee, P. Mongolian ICT industry achievements and prospects. Turk. Altaic Econ. Belt 2018, $22,34-41$.

71. Mundur, B.; Chandaga, U.; Narantsogt, G.; Jagdagsuren, D.; Magsar, T.; Minjuur, E.; Shijee, N.; Gombodorj, A.; Agvaandaram, G.; Dorjsuren, T. Prevalence of Syphilis and HIV Diseases among Some Universities' Students in Mongolia. J. Health Sci. 2017, 5, 298-302.

72. WHO. World Health Statistics 2021: Monitoring Health for the SDGs; WHO: Geneva, Switzerland, 2021; pp. 1-132.

73. Human Development Reports. Available online: http://hdr.undp.org/en/content/human-development-index-hdi (accessed on 22 October 2021).

74. UNESCO. UNESCO Institute for Statistics; UNESCO: Montreal, QC, Canada, 2010.

75. Barro, R.J.; Lee, J.-W. A New Data Set of Educational Attainment in the World, 1950-2010. 2010. Available online: https://www.nber. org/papers/w15902 (accessed on 11 August 2021). 